\title{
Discordances between phylogenetic and morphological patterns in alpine leaf beetles attest to an intricate biogeographic history of lineages in postglacial Europe
}

\author{
Y. TRIPONEZ, ${ }^{*}$ S. BUERKI, + M. BORER,${ }^{*}$ R. E. NAISBIT, ${ }^{*} \ddagger$ M. RAHIER ${ }^{*}$ and N. ALVAREZ \\ *Laboratory of Evolutionary Entomology, Institute of Biology, University of Neuchâtel, Rue Emile-Argand 11, 2000 Neuchâtel, \\ Switzerland, +Molecular Systematics Section, Jodrell Laboratory, Royal Botanic Gardens, Kew, Richmond, Surrey TW9 3DS, \\ UK, łUnit of Ecology and Evolution, Department of Biology, University of Fribourg, Chemin du Musée 10, 1700 Fribourg, \\ Switzerland, §Department of Ecology and Evolution, Biophore Building, University of Lausanne, 1015 Lausanne, Switzerland
}

\begin{abstract}
Pleistocene glacial and interglacial periods have moulded the evolutionary history of European cold-adapted organisms. The role of the different mountain massifs has, however, not been accurately investigated in the case of high-altitude insect species. Here, we focus on three closely related species of non-flying leaf beetles of the genus Oreina (Coleoptera, Chrysomelidae), which are often found in sympatry within the mountain ranges of Europe. After showing that the species concept as currently applied does not match barcoding results, we show, based on more than 700 sequences from one nuclear and three mitochondrial genes, the role of biogeography in shaping the phylogenetic hypothesis. Dating the phylogeny using an insect molecular clock, we show that the earliest lineages diverged more than 1 Mya and that the main shift in diversification rate occurred between 0.36 and 0.18 Mya. By using a probabilistic approach on the parsimony-based dispersal/vicariance framework (MP-DIVA) as well as a direct likelihood method of state change optimization, we show that the Alps acted as a cross-roads with multiple events of dispersal to and reinvasion from neighbouring mountains. However, the relative importance of vicariance vs. dispersal events on the process of rapid diversification remains difficult to evaluate because of a bias towards overestimation of vicariance in the DIVA algorithm. Parallels are drawn with recent studies of cold-adapted species, although our study reveals novel patterns in diversity and genetic links between European mountains, and highlights the importance of neglected regions, such as the Jura and the Balkanic range.
\end{abstract}

Keywords: lineage diversification, MP-DIVA, Oreina, phylogeography, Pleistocene, species concept

\section{Introduction}

Pleistocene glacial periods, beginning around two million years ago, strongly affected species over large parts of their ranges, with most populations becoming

Correspondence: Yann Triponez, Fax: +41 32718 2103; E-mail: yann.triponez@unine.ch

Y.T. and S.B. contributed equally to this work and should be considered co-first authors. M.B. and R.E.N. contributed equally to this work and should be considered co-third authors. extinct, dispersing to new locations or surviving in restricted refugial areas (e.g., Coope 1994; Hewitt 2000; Schmitt 2007). As the climate warmed again, they recolonized the previously ice-covered areas. In the last decade, sequence-based phylogeographic studies have revealed that the biogeographic histories of temperate and arctic-alpine species were likely to be different (e.g., Hewitt 2001; Schmitt et al. 2005). Temperate species survived during cold periods in southern refugia in Iberia, Italy, the Balkans, the Caucasus region and even Northern Africa (Habel et al. 2008), repopulating north- 
ern Europe after the last glacial maximum and creating hybrid zones in the areas where the expanding genomes met (Hewitt 2000). In contrast, alpine species (or those with an arctic-alpine disjunct distribution) must have been widespread during glacial maxima (Haubrich \& Schmitt 2007) and probably inhabited the cold steppes that were present over most of Europe (Willis \& van Andel 2004). Such cold-adapted species were restricted to remote environments during interglacial stages like the present (Hewitt 2004; Schmitt et al. 2006). As a consequence, some species with formerly large distributions continue to persist only as relict species in relatively small areas (e.g., Shapiro et al. 2004; Dalén et al. 2007; Stewart et al. 2010).

Most large-scale phylogeographic studies from coldadapted organisms have found strong differentiation among populations (and among biogeographic regions) (Alvarez et al. 2009; Schmitt 2009). However, little is known regarding the respective influence of the different European mountains on the fate of currently isolated populations (spread through different massifs) that were likely to have been connected in the past. In this context, one might hypothesize a marked pattern of isolation by distance, with disjunctive areas of the distribution being highly isolated genetically from each other (as shown in Varga \& Schmitt 2008).

In this study, we propose to investigate such evolutionary questions focusing on cold-adapted organisms using three closely related species of the leaf beetle genus Oreina (Coleoptera, Chrysomelidae)—namely O. alpestris, O. ganglbaueri and O. speciosa (Hsiao \& Pasteels 1999)—as a case study. As a whole, this genus-comprising ca. 28 species described mainly on the basis of characters related to male genitalia (Kippenberg 1994, 2008) and feeding exclusively either on the Apiaceae or Asteraceae plant families (Jolivet et al. 1986) - is distributed throughout the mountains of Europe (except Scandinavia), with some incursions into the lowlands, and western Siberia. In addition to exhibiting an appropriate pattern of distribution to investigate postglacial recolonization processes in high-elevation species, most of these beetles are usually recorded as flightless (Kalberer et al. 2005), a feature that might have further limited their dispersal abilities. Molecularbased analyses on other Oreina species have suggested that populations were generally highly isolated (Knoll \& Rowell-Rahier 1998; Margraf et al. 2007; Borer et al. 2010). Such a pattern was explained by slow postglacial recolonization in organisms having low dispersal abilities. However, this study treats a beetle group showing a much wider spatial distribution than those previously analysed.

In addition to being genetically closely related (Hsiao \& Pasteels 1999), these three species share many characteristics such as their external morphology, shape of the male genitalia, highly variable warning coloration and autogenous cardenolide production (Dobler et al. 1996; Triponez et al. 2007). These oligophagous beetles feed on various Apiaceae species (mainly from genera Heracleum, Peucedanum, Chaerophyllum, Angelica or Aegopodium), from which they capture chemical compounds and reinvest them into their own defence (Hsiao \& Pasteels 1999). These sister species have different ranges across the European mountains: $O$. alpestris is a common inhabitant of most mountain regions between the Pyrenean-Cantabric range and the Carpathians; O. speciosa is restricted to the Alps, the Jura, the Massif Central and the northern Balkans; finally, O. ganglbaueri is a recognized Pyrenean-Cantabric endemic. They share the same alpine environment in open habitats close to or in the understorey of mixed deciduous-coniferous or coniferous forests, with beech, fir, spruce or larch as dominant woody species (Kippenberg 1994; Jolivet et al. 1986; Y. Triponez, pers. obs.) at elevations from 800 to $2200 \mathrm{~m}$. asl.; in the upper parts of the range, pure high forbs can shelter these beetles in moist places, and in extreme cases, they can even be found in stone runs with scarce plant cover where they hide under rocks during the day (M. Borer, pers. obs.). As the three species can feed on the same hosts, it is common to find pairs of them in sympatry, especially in the Alps and Pyrenees.

The main goal of this study is to examine the phylogeographic patterns of these leaf beetles to infer whether or not lineages present a marked pattern of isolation by distance. Moreover, we extend the question to address the spatiotemporal framework of the evolutionary events that drove diversification of lineages and moulded the spatial genetic structure of alpine organisms. In view of their ecological and morphological similarities, we expect the three leaf beetle species O. alpestris, $O$. ganglbaueri and O. speciosa to be associated with closely related genetic lineages that evolved recently and spread over the different European mountain massifs during the Pleistocene. The working hypotheses of the study are as follows:

1 Given the impact of Pleistocene climatic oscillations on alpine biota, we hypothesize that these leaf beetles show a pattern of differentiation that reflects the alternate expansion during glacial period and isolation during temperate interglacials.

2 The alpine arc, because of its central geographical position between other European massifs, should harbour higher lineage diversity than neighbouring mountains and stand as a key cross-roads where different lineages admix. 
To test these hypotheses, the spatiotemporal evolution of the three closely related species of Oreina was inferred using phylogenetic, divergence time and diversification analyses based on a large sampling spanning the distribution of these taxa. Before studying fine-scale evolutionary processes, species circumscriptions and phylogenetic relationships were investigated by applying a phylogenetic barcoding approach (see Borer et al. 2010) and studying key morphological characters. Thanks to our multiple-facetted phylogeographic approach, we will be able to determine which cold or temperate Pleistocene periods and which European mountains have impacted the most on the O. alpestris, $O$. ganglbaueri and O. speciosa genetic lineages outbreak and diversification. The main trends observed in Oreina will also be discussed in the framework of previous studies on European alpine phylogeography.

\section{Material and methods}

\section{Sampling and species determination}

Sites within the main European mountain ranges were visited during the summers of 2005-2007. In total, the three sister species-O. alpestris (Schumm.), O. ganglbaueri (Jakob) and O. speciosa (L.), hereafter referred to as the Oreina AGS complex-were collected in 63 sites (see Table 1) with a total of 211 specimens (mostly males). All sampled insects were determined, mostly on the basis of male genitalia shape and with the help of some external morphological features for females, following Kippenberg (1994, 2008). In the Oreina AGS complex, Kippenberg (1994, 2008) defined seven types of male genitalia: one specific to O. speciosa, one for O. ganglbaueri and five within $O$. alpestris (defined along a morphological continuum and according to geographical distributions). The different subtypes of $O$. alpestris and respective distributions are as follows: O. alpestris ssp. alpestris (Schumm.) in the northern Carpathians (and Sudetes), ssp. banatica (Wse.) in the southern Carpathians and southern Balkans, ssp. marsicana (Luig.) in the Apennines, ssp. nigrina (Suffr.) in the Pyrenees and Cantabric range, and finally ssp. variabilis (Wse.) in the Alps, northern Balkans and Black Forest. Outgroups were sampled among four closely related species (Hsiao \& Pasteels 1999), namely O. bifrons (Fab.), O. cacaliae (Schr.), O. gloriosa (Fab.) and O. liturata (Scop.).

\section{DNA extraction, PCR amplification and cycle sequencing}

Total genomic DNA was extracted from an average of three individuals per population, using the DNeasy ${ }^{\circledR}$
Tissue Kit (Qiagen, Hilden, Germany) on a sample of 4-6 legs of each individual. One nuclear region and three mtDNA regions were amplified using the following primers: partial internal transcribed spacer (ITS2) region (ITS3 and ITS4 primers from Gomez-Zurita \& Vogler 2003), 16s ribosomal RNA (16s rRNA) (LR-N13398 and LR-J-12 883 primers from Simon et al. 1994), partial cytochrome oxidase I (COI) (C1-J-1751 and C1$\mathrm{N}-2191$ primers from Simon et al. 1994) and partial cytochrome oxidase II (COII) (modTL2-J-3037 and modC2-N-3661 primers from Mardulyn et al. 1997). Amplifications were carried out in a standard 30- $\mu \mathrm{L}$ PCR reaction including $3 \mu \mathrm{L}$ of $10 \times$ PCR buffer (Promega, Madison, WI, USA), $3 \mu \mathrm{L}$ of a $\mathrm{MgCl}_{2}$ solution ( $25 \mathrm{~mm}$ ), $3 \mu \mathrm{L}$ of dNTPs (1.5 mM), $0.5 \mu \mathrm{L}$ of forward and reverse primers $(10 \mathrm{~mm}), 0.3 \mu \mathrm{L}$ of Taq DNA polymerase (Promega, Madison, WI, USA), $3 \mu \mathrm{L}$ of extracted DNA, all made up to $30 \mu \mathrm{L}$ with purified MilliQ water. The PCRs were run in a TGradient thermocycler (Biometra, Goettingen, Germany) with the following programme: initial denaturation at $93{ }^{\circ} \mathrm{C}$ for $1 \mathrm{~min} 30 \mathrm{~s}$; 35 cycles comprising denaturation steps at $93^{\circ} \mathrm{C}$ for $1 \mathrm{~min} 30 \mathrm{~s}$, annealing steps at $45^{\circ} \mathrm{C}\left(16 \mathrm{~s}\right.$ rRNA, COI) or at $53{ }^{\circ} \mathrm{C}$ (COII, ITS2) for $1 \mathrm{~min}$, extension steps at $72{ }^{\circ} \mathrm{C}$ for $2 \mathrm{~min}$; and final extension at $72{ }^{\circ} \mathrm{C}$ for $8 \mathrm{~min}$. The PCR product purification and sequencing was carried out by Macrogen (Seoul, South Korea). Sequencing was performed with both forward and reverse primers under BigDye ${ }^{\mathrm{TM}}$ terminator cycling conditions, purifying the reacted products by using ethanol precipitation and running them on an Automatic Sequencer 3730XL (Applied Biosystem, Foster City, USA).

\section{Sequence alignment and congruence between data sets}

Sequences (forward and reverse) were manually edited and assembled using the software CHROMAs PRO 1.34 (Technelysium, Helensvale, Australia). Alignments of ITS2 and 16s rRNA were carried out using CLUSTALW multiple alignment (Thompson et al. 1997) implemented in the software BioEDIT 7.0.5.3 (Hall 1999), followed by minor manual correction. For COI and COII, alignments were trivial as all sequenced fragments were of the same size. The best-fit substitution model was chosen for each partition using MrAIC.pl 1.4.3 (Nylander 2004) based on the Akaike information criterion (AIC; Akaike 1974). The three mtDNA partitions were shown to be congruent using the mILD test (Planet \& Sarkar 2005), and a supermatrix comprising 16s rRNA, COI and COII was built. In contrast, the mILD analysis revealed that ITS2 was incongruent with the mtDNA regions $(P<0.05)$, and it was treated separately.

Before inferring the phylogeny and biogeographic history of the ingroup, preliminary analyses were per- 
Table 1 Geographic distribution of sampled populations. Species occuring in each location are also provided

\begin{tabular}{|c|c|c|c|c|c|c|}
\hline $\begin{array}{l}\text { Mountain Range } \\
\text { (biogeographic area } \\
\text { according to Fig. 4) }\end{array}$ & Country & Code & Location & Altitude & Geographical coordinates & Species \\
\hline \multirow[t]{39}{*}{ Alps (b) } & Austria & AUT1 & Arlbergpass & 1354 & N $47^{\circ} 08^{\prime} 03.80^{\prime \prime}$ E $010^{\circ} 12^{\prime} 20.90^{\prime \prime}$ & O. speciosa \\
\hline & Austria & AUT2 & Mittersill (Gamsblick) & 1317 & $\mathrm{~N} 47^{\circ} 11^{\prime} 25.20^{\prime \prime}$ E $012^{\circ} 28^{\prime} 37.50^{\prime \prime}$ & O. speciosa \\
\hline & Austria & AUT3 & Badgastein (Stubnerkogel) & 1876 & N $47^{\circ} 06^{\prime} 35.40^{\prime \prime}$ E $013^{\circ} 07^{\prime} 36.20^{\prime \prime}$ & O. alpestris \\
\hline & Austria & AUT5 & Koralpe & 1564 & N $46^{\circ} 48^{\prime} 30.50^{\prime \prime}$ E $014^{\circ} 56^{\prime} 34.10^{\prime \prime}$ & O. speciosa \\
\hline & Austria & GRH & Grosser Hengst & 1615 & N $47^{\circ} 27^{\prime} 06.15^{\prime \prime}$ E $014^{\circ} 25^{\prime} 50.86^{\prime \prime}$ & O. speciosa \\
\hline & Austria & VAL & Valentinsalm & 1540 & N 46 $36^{\prime} 29.48^{\prime \prime}$ E $012^{\circ} 57^{\prime} 18.89^{\prime \prime}$ & $\begin{array}{l}\text { O. alpestris/ } \\
\text { O. speciosa }\end{array}$ \\
\hline & France & FR11 & Col du Galibier & 1999 & 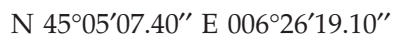 & O. speciosa \\
\hline & France & FR13 & Ailefroide & 1700 & N $44^{\circ} 53^{\prime} 41.50^{\prime \prime}$ E $006^{\circ} 26^{\prime} 44.70^{\prime \prime}$ & O. speciosa \\
\hline & France & FR14 & Abries & 1886 & N $44^{\circ} 48^{\prime} 49.10^{\prime \prime}$ E $006^{\circ} 58^{\prime} 28.30^{\prime \prime}$ & O. speciosa \\
\hline & France & FR16 & Saint-Martin Vesubie & 1795 & $\mathrm{~N} 44^{\circ} 06^{\prime} 37.10^{\prime \prime}$ E $007^{\circ} 18^{\prime} 41.10^{\prime \prime}$ & O. speciosa \\
\hline & Italy & DOL2 & Passo Rolle & 1969 & N $46^{\circ} 17^{\prime} 46.00^{\prime \prime}$ E $011^{\circ} 46^{\prime} 56.00^{\prime \prime}$ & O. speciosa \\
\hline & Italy & DOL3 & Passo Duran & 1477 & N $46^{\circ} 18^{\prime} 45.20^{\prime \prime}$ E $012^{\circ} 05^{\prime} 29.20^{\prime \prime}$ & O. speciosa \\
\hline & Italy & IT1 & Col du Petit St-Bernard & 1996 & N $45^{\circ} 42^{\prime} 12.00^{\prime \prime}$ E $006^{\circ} 52^{\prime} 29.40^{\prime \prime}$ & O. speciosa \\
\hline & Italy & IT2 & Passo Pian delle Fugazze & 1296 & N $45^{\circ} 44^{\prime} 47.30^{\prime \prime}$ E $011^{\circ} 09^{\prime} 32.30^{\prime \prime}$ & O. alpestris \\
\hline & Italy & IT3 & Monte Baldo & 1247 & N $45^{\circ} 47^{\prime} 03.60^{\prime \prime}$ E $010^{\circ} 52^{\prime} 14.00^{\prime \prime}$ & O. speciosa \\
\hline & Italy & IT4 & Val Daone & 1319 & N $46^{\circ} 01^{\prime} 19.80^{\prime \prime}$ E $010^{\circ} 30^{\prime} 47.60^{\prime \prime}$ & O. speciosa \\
\hline & Italy & IT5 & Passo del Tonale & 1784 & N $46^{\circ} 15^{\prime} 53.40^{\prime \prime}$ E $010^{\circ} 36^{\prime} 46.80^{\prime \prime}$ & O. speciosa \\
\hline & Italy & IT8 & Terme di Valdieri & 1419 & N $44^{\circ} 12^{\prime} 10.30^{\prime \prime}$ E $007^{\circ} 16^{\prime} 13.60^{\prime \prime}$ & O. speciosa \\
\hline & Italy & IT9 & Crissolo (Piano del Re) & 1342 & N $44^{\circ} 41^{\prime} 59.00^{\prime \prime}$ E $007^{\circ} 09^{\prime} 11.20^{\prime \prime}$ & O. speciosa \\
\hline & Italy & IT11 & Breuil-Cervinia & 2149 & N $45^{\circ} 55^{\prime} 40.10^{\prime \prime}$ E $007^{\circ} 37^{\prime} 53.30^{\prime \prime}$ & O. speciosa \\
\hline & Italy & IT12 & Macugnaga & 1343 & N 455ㄱㄷㅗ.50" E $007^{\circ} 56^{\prime} 14.00^{\prime \prime}$ & O. speciosa \\
\hline & Slovenia & SLO2 & Predmeja & 1142 & N $45^{\circ} 55^{\prime} 56.70^{\prime \prime}$ E $013^{\circ} 50^{\prime} 31.20^{\prime \prime}$ & O. speciosa \\
\hline & Slovenia & SLO8 & Logarska Dolina & 1394 & N $46^{\circ} 22^{\prime} 09.50^{\prime \prime}$ E $014^{\circ} 35^{\prime} 04.70^{\prime \prime}$ & O. speciosa \\
\hline & Slovenia & SLO9 & Dom na Komni & 1261 & N $46^{\circ} 16^{\prime} 58.10^{\prime \prime}$ E $013^{\circ} 47^{\prime} 13.40^{\prime \prime}$ & O. speciosa \\
\hline & Slovenia & SLO10 & Vrsic pass & 1387 & N $46^{\circ} 25^{\prime} 29.00^{\prime \prime}$ E $013^{\circ} 44^{\prime} 34.60^{\prime \prime}$ & O. speciosa \\
\hline & Switzerland & AI1 & Brulisau & 1600 & N $47^{\circ} 17^{\prime} 04.08^{\prime \prime}$ E $009^{\circ} 29^{\prime} 05.90^{\prime \prime}$ & $\begin{array}{l}\text { O. alpestris/ } \\
\text { O. speciosa }\end{array}$ \\
\hline & Switzerland & BE1 & Kandersteg & 1314 & 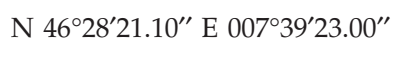 & $\begin{array}{l}\text { O. alpestris/ } \\
\text { O. speciosa }\end{array}$ \\
\hline & Switzerland & GL1 & Schwanden & 1500 & N 46 $57^{\prime} 28.30^{\prime \prime}$ E $009^{\circ} 05^{\prime} 55.90^{\prime \prime}$ & O. speciosa \\
\hline & Switzerland & GR1 & Tschiertschen & 1400 & N $46^{\circ} 48^{\prime} 42.00^{\prime \prime}$ E $009^{\circ} 36^{\prime} 40.00^{\prime \prime}$ & $\begin{array}{r}\text { O. alpestris/ } \\
\text { O. speciosa }\end{array}$ \\
\hline & Switzerland & LOT & Lotschental & 1888 & 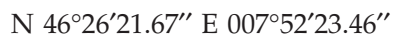 & O. speciosa \\
\hline & Switzerland & SUR & Sur & 1515 & N 463'ㅅ․ $16.40^{\prime \prime}$ E $009^{\circ} 37^{\prime} 27.00^{\prime \prime}$ & O. speciosa \\
\hline & Switzerland & SUS & Susch & 1486 & 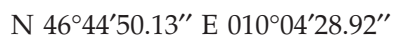 & O. speciosa \\
\hline & Switzerland & VD1 & Col des Mosses & 1843 & N $46^{\circ} 23^{\prime} 13.93^{\prime \prime}$ E $007^{\circ} 07^{\prime} 48.60^{\prime \prime}$ & $\begin{array}{l}\text { O. alpestris/ } \\
\text { O. speciosa }\end{array}$ \\
\hline & Switzerland & VS2 & Sanetsch & 1680 & N 46 $18^{\circ} 26.66^{\prime \prime}$ E $007^{\circ} 20^{\prime} 07.46^{\prime \prime}$ & O. speciosa \\
\hline & Switzerland & VS4 & Saas Almagell & 1620 & 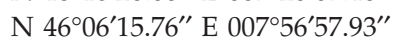 & O. speciosa \\
\hline & Switzerland & VS5 & Les Haudères & 1436 & N $46^{\circ} 04^{\prime} 52.00^{\prime \prime}$ E $007^{\circ} 30^{\prime} 18.10^{\prime \prime}$ & O. speciosa \\
\hline & Switzerland & VS6 & Emosson & 1944 & N $46^{\circ} 03^{\prime} 55.30^{\prime \prime}$ E $006^{\circ} 55^{\prime} 43.90^{\prime \prime}$ & O. speciosa \\
\hline & Switzerland & VS7 & Chandolin & 2000 & N $46^{\circ} 14^{\prime} 41.85^{\prime \prime}$ E $007^{\circ} 36^{\prime} 10.01^{\prime \prime}$ & O. speciosa \\
\hline & Switzerland & VS8 & La Fouly & 1571 & N $45^{\circ} 56^{\prime} 10.20^{\prime \prime}$ E $007^{\circ} 05^{\prime} 36.10^{\prime \prime}$ & O. speciosa \\
\hline \multirow{3}{*}{$\begin{array}{l}\text { Abruzzi } \\
\text { Appenines (a) }\end{array}$} & Italy & ABZ1 & Vado di Sole & 1650 & N $42^{\circ} 23^{\prime} 51.70^{\prime \prime}$ E $013^{\circ} 47^{\prime} 19.40^{\prime \prime}$ & O. alpestris \\
\hline & Italy & ABZ2 & Sarnano1 & 1333 & $\mathrm{~N} 42^{\circ} 58^{\prime} 57.40^{\prime \prime}$ E $013^{\circ} 15^{\prime} 00.20^{\prime \prime}$ & O. alpestris \\
\hline & Italy & ABZ5 & Sarnano2 & 1431 & N $43^{\circ} 01^{\prime} 27.90^{\prime \prime}$ E $013^{\circ} 13^{\prime} 25.20^{\prime \prime}$ & O. alpestris \\
\hline $\begin{array}{l}\text { Ligurian } \\
\text { Appenines (h) }\end{array}$ & Italy & IT7 & Passo del Penice & 1141 & $\mathrm{~N} 44^{\circ} 47^{\prime} 26.20^{\prime \prime}$ E $009^{\circ} 18^{\prime} 12.70^{\prime \prime}$ & O. alpestris \\
\hline Black Forest (d) & Germany & SW3 & Zastler & 1068 & N $47^{\circ} 54^{\prime} 13.40^{\prime \prime}$ E $007^{\circ} 58^{\prime} 58.00^{\prime \prime}$ & O. alpestris \\
\hline $\begin{array}{l}\text { Cantabric } \\
\text { Range (e) }\end{array}$ & Spain & EUR & Pico de Europa & 1295 & $\mathrm{~N} 43^{\circ} 07^{\prime} 40.44^{\prime \prime} \mathrm{W} 004^{\circ} 52^{\prime} 38.82^{\prime \prime}$ & O. alpestris \\
\hline
\end{tabular}


Table 1 (Continued)

\begin{tabular}{|c|c|c|c|c|c|c|}
\hline $\begin{array}{l}\text { Mountain Range } \\
\text { (biogeographic area } \\
\text { according to Fig. 4) }\end{array}$ & Country & Code & Location & Altitude & Geographical coordinates & Species \\
\hline \multirow[t]{4}{*}{$\begin{array}{l}\text { Carpathians and } \\
\text { Sudetes (f) }\end{array}$} & $\begin{array}{l}\text { Czech } \\
\text { Republic }\end{array}$ & $\mathrm{CZ4}$ & Karlova Studanka & 1267 & N $50^{\circ} 04^{\prime} 13.30^{\prime \prime}$ E $017^{\circ} 14^{\prime} 42.30^{\prime \prime}$ & O. alpestris \\
\hline & Poland & PL2 & Zakopane & 1016 & 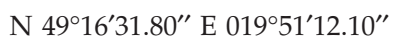 & O. alpestris \\
\hline & Romania & RO1 & Monti Rodnei & 1111 & N $47^{\circ} 35^{\prime} 54.90^{\prime \prime}$ E $024^{\circ} 55^{\prime} 21.20^{\prime \prime}$ & O. alpestris \\
\hline & Romania & $\mathrm{RO} 2$ & Sinaia & 1386 & $\mathrm{~N} 45^{\circ} 21^{\prime} 26.50^{\prime \prime}$ E $025^{\circ} 31^{\prime} 05.70^{\prime \prime}$ & O. alpestris \\
\hline \multirow[t]{4}{*}{ Balkanic Range (c) } & Croatia & HR2 & Risnjak & 1402 & $\mathrm{~N} 45^{\circ} 25^{\prime} 39.50^{\prime \prime}$ E $014^{\circ} 37^{\prime} 19.40^{\prime \prime}$ & O. speciosa \\
\hline & Croatia & HR4 & Sjeverni Velebit & 1422 & N $44^{\circ} 48^{\prime} 28.00^{\prime \prime}$ E $014^{\circ} 58^{\prime} 14.70^{\prime \prime}$ & O. speciosa \\
\hline & Montenegro & MON2 & Savnik (Slatina) & 1363 & $\mathrm{~N} 42^{\circ} 59^{\prime} 55.50^{\prime \prime}$ E $019^{\circ} 09^{\prime} 58.00^{\prime \prime}$ & O. alpestris \\
\hline & Serbia & SER1 & Kopaonik & 1700 & $\mathrm{~N} 43^{\circ} 20^{\prime} 32.40^{\prime \prime}$ E $020^{\circ} 46^{\prime} 01.90^{\prime \prime}$ & O. alpestris \\
\hline \multirow[t]{4}{*}{ Jura $(g)$} & France & FR1 & Cret de la Neige & 1715 & N $46^{\circ} 15^{\prime} 04.96^{\prime \prime}$ E $005^{\circ} 55^{\prime} 28.54^{\prime \prime}$ & O. speciosa \\
\hline & Switzerland & JU1 & Undervelier & 550 & N $47^{\circ} 17^{\prime} 57.06^{\prime \prime}$ E $007^{\circ} 13^{\prime} 24.32^{\prime \prime}$ & O. speciosa \\
\hline & Switzerland & NE1 & Motiers & 760 & N 46 $54^{\prime} 09.63^{\prime \prime}$ E $006^{\circ} 36^{\prime} 59.38^{\prime \prime}$ & O. speciosa \\
\hline & Switzerland & SO1 & Weissenstein & 1274 & $\mathrm{~N} 47^{\circ} 15^{\prime} 03.40^{\prime \prime}$ E $007^{\circ} 29^{\prime} 07.70^{\prime \prime}$ & O. speciosa \\
\hline \multirow[t]{2}{*}{ Massif Central (j) } & France & FR8 & Puy Mary & 1550 & N $45^{\circ} 06^{\prime} 40.90^{\prime \prime}$ E $002^{\circ} 40^{\prime} 51.80^{\prime \prime}$ & O. speciosa \\
\hline & France & FR9 & Puy de Dome & 1292 & N $45^{\circ} 46^{\prime} 07.70^{\prime \prime}$ E $002^{\circ} 57^{\prime} 33.70^{\prime \prime}$ & O. speciosa \\
\hline \multirow[t]{4}{*}{ Pyrenees (i) } & France & FR3 & Vernet-les-Bains & 1737 & $\mathrm{~N} 42^{\circ} 30^{\prime} 00.20^{\prime \prime}$ E $002^{\circ} 24^{\prime} 30.40^{\prime \prime}$ & O. alpestris \\
\hline & France & FR4 & Col de Port & 1334 & $\mathrm{~N} 42^{\circ} 53^{\prime} 39.10^{\prime \prime}$ E $001^{\circ} 26^{\prime} 50.40^{\prime \prime}$ & O. alpestris \\
\hline & France & FR5 & Col de Peyresourde & 1548 & $\mathrm{~N} 42^{\circ} 47^{\prime} 50.00^{\prime \prime}$ E $000^{\circ} 27^{\prime} 10.60^{\prime \prime}$ & O. ganglbaueri \\
\hline & Spain & SP1 & Salardu & 1636 & $\mathrm{~N} 42^{\circ} 39^{\prime} 57.90^{\prime \prime}$ E $000^{\circ} 55^{\prime} 06.70^{\prime \prime}$ & $\begin{array}{l}\text { O. alpestris/ } \\
\text { O. ganolbaueri }\end{array}$ \\
\hline
\end{tabular}

formed on the mtDNA data set to investigate (i) the distribution of genetic diversity (per population) and (ii) the taxonomic and phylogenetic species concepts, by applying a COI-based barcoding approach.

\section{Genetic diversity}

For each population, the nucleotide diversity (Nei 1987) was calculated on the mtDNA data set using the nuc.div function implemented in the $R$ package PEGAS (Paradis 2010). This function computes the sum of the number of differences between pairs of sequences divided by the number of comparisons. These values were plotted on a map using ARCGIS 9.1 (ESRI, Redlands, CA, USA). Such an approach will provide evidence to understand the biogeographic history of the ingroup.

\section{Barcoding analyses}

Pairwise Kimura-2P (K2P) distances were calculated among specimens based on the COI data set using the $R$ package APE (Paradis et al. 2004) following Borer et al. (2010). The COI region has proven to be a useful barcoding region for animals (Hebert et al. 2004) and might consequently provide valuable information for taxon circumscription within the ingroup. In this study, we used the information provided by the K2P model (see Wiemers \& Fiedler 2007) and computed withiningroup and ingroup-outgroup distances to assess the validity of the following entities: (i) the Oreina AGS complex (with regard to the outgroups), (ii) the taxonomic species separately and (iii) the major phylogenetic clades. In the case of the latter, the barcoding approach was combined with the phylogenetic analyses to define major clades.

\section{Phylogenetic inference}

To estimate phylogenetic relationships among individuals, both the mtDNA supermatrix and the ITS2 alignment were analysed using parsimony ratchet (Nixon 1999) as implemented in PAUPrat (Sikes \& Lewis 2001). Based on recommendations by Nixon (1999), ten independent searches were performed with 200 iterations and $15 \%$ of the parsimony informative characters perturbed using PAUP* version 4.0b10 (Swofford 2002). The shortest equally most parsimonious trees were combined to produce a majority-rule consensus tree. Node support was determined by computing Bremer support values as implemented in TREeRot.v3 (Sorenson \& Franzosa 2007) and using PAUP* version $4.0 \mathrm{~b} 10$ (Swofford 2002) with MAXTREES $=1000$ and nreps $=10$.

Bayesian analyses were also performed separately for the ITS2 region and the mtDNA supermatrix (treating the three regions as separate partitions; following $\mathrm{Ny}$ lander et al. 2004) using MRBAYEs version 3.1 (Huelsenbeck \& Ronquist 2001) with substitution models as estimated by MrAIC.pl 1.4.3 (Nylander 2004) and four 
estimated alpha categories for the gamma shape (Yang 1994). Four simultaneous Monte Carlo Markov chains were run for $10^{8}$ generations in two independent runs, saving a tree every 1000 generations. Convergence of the MCMC runs was tested by computing the Potential Scale Reduction Factor (Gelman \& Rubin 1992) as implemented in MRBAYES and by determining the effective sample size using Tracer 1.4.1 (Rambaut \& Drummond 2008). Accordingly, the burn-in period was set to $3 \times 10^{7}$ generations until stationarity in the likelihood value was established among the runs, so that 30000 sample points were discarded. The last 70000 trees were used to calculate the half-compatible topology (i.e., majority-rule) and the Bayesian posterior probability (BPP) at each node. Bremer support values were also determined on the half-compatible topology (see above for the methodology)

To further test the congruence between the mtDNA and ITS data sets, the Kishino-Hasegawa test-implemented in PAUP* version 4.0b10 (Swofford 2002)—was performed on the maximum parsimony (MP) mtDNA and ITS consensus trees.

\section{Spatial genetic structure}

Based on the topologies and node supports obtained for mtDNA and ITS2 phylogenetic analyses, supported clades were defined and then displayed on geographical maps using ARCGIS 9.1 (ESRI, Redlands, CA, USA), by representing each population as a pie chart showing the number of samples from each clade.

\section{Biogeographic analysis}

Based on the distribution of specimens of the Oreina AGS complex and on geographical/topographical evidence, ten areas were defined as follows: (a) Abruzzi Appenines, (b) Alps, (c) Balkanic range, (d) Black Forest, (e) Cantabric range, (f) Carpathians and Sudetes, (g) Jura, (h) Ligurian Appenines, (i) Pyrenees and (j) Massif Central. Following the same approach as in Espíndola et al. (2010), terminals were coded according to the location of each population.

To account for uncertainty in phylogenetic relationships, dispersal-vicariance analyses (DIVA; Ronquist 1997) were performed over a set of trees and subsequently summarized on a reference tree. To confirm the results obtained by the previous method, the Oreina AGS ancestral area reconstruction was also inferred using the likelihood method implemented in Mesquite v2.73 (Maddison \& Maddison 2010; please see below for details).

The program DIVA (Ronquist 1996) was run over the best trees of the MP analysis (125 in total) with a maxi- mum number of areas equal to two, and scripts (available on request to $\mathrm{SB}$ ) were used to summarize/average ancestral area reconstructions over all sampled trees for each node of the MP consensus tree. This approach-similar to Bayes-DIVA developed by $\mathrm{Ny}$ lander et al. (2008) — will be hereafter referred to as MPDIVA. The DIVA method infers the most parsimonious reconstruction of ancestral ranges on a given phylogenetic tree by minimizing the number of dispersal and extinction events that are needed to explain the current terminal distributions (Ronquist 1997). The DIVA reconstruction is subdivided into two main components: (a) anagenetic evolution (internode) and (b) cladogenetic range evolution (speciation processes taking place at nodes). The first component is modelled using a threedimensional cost matrix to estimate the cost of moving from the ancestor to each of the descendants (Ronquist 1997). The second component allows two different scenarios for area range inheritance at nodes: (i) duplication or within-area speciation when the ancestor is distributed in a single area and each of the two descendants inherits the entire ancestral range (e.g., A to A); (ii) vicariance when the ancestor occurs in two or more areas and each descendant inherits a non-overlapping subset of the ancestral range (e.g., AB to A and B). Only one dispersal event per branch (between two ancestral nodes) is allowed in the model, except for terminal branches leading to widespread taxa, for which DIVA postulates multiple dispersal events. As raised by several authors (see Buerki et al. 2011 for a review), this particularity of DIVA tends to (i) overestimate vicariance events in the internal branches and (ii) postpone dispersals to terminal branches. To account for polytomies in our consensus, tree exceptions were introduced following the same approach as in Espíndola et al. (2010). The main routes of dispersal within the Oreina AGS complex (both until the definition of main clades and within terminal clades) were plotted on maps based on dispersal contingency tables built from the output of MP-DIVA using $R$ scripts ( $\mathrm{R}$ Development Core Team 2009; available on request to SB).

The likelihood ancestral area reconstruction of the Oreina AGS complex was inferred on the Penalized likelihood (PL; Sanderson 2002) dated consensus trees using Mesquite v2.73 (Maddison \& Maddison 2010) with the Markov $k$-state one-parameter model ( $\mathrm{Mk} 1$; see below for more details on the applied methodology). The subsequent ancestral area reconstruction and biogeographic scenarios were summarized following the same approach as in MP-DIVA. An advantage of the method implemented in Mesquite over DIVA is its ability to take into account branch lengths and polytomies while reconstructing the biogeographic scenario. On the other hand, unlike DIVA, Mesquite does not allow (i) consid- 
eration of polymorphic characters and (ii) modelling of cladogenetic range evolution (i.e., a change in ancestral area reconstruction has to be interpreted as a combination of biogeographic events). With the only exception of the outgroup taxa (which were removed for the analysis), all terminals are restricted to one area. In this context, the fact that Mesquite does not allow polymorphic characters is not problematic. On the other hand, the lack of a proper cladogenetic range evolution model might be more challenging for the interpretation of biogeographic results [i.e., biogeographic events (dispersal, extinction or vicariance) on branches have to be inferred a posteriori]. The likelihood approach implemented in the program Lagrange (Ree \& Smith 2008) could not be used to circumvent this issue mainly because of polytomies in the data (i.e., the Lagrange program requires input trees that are ultrametric and fully resolved, an assumption that was not respected by the PL consensus tree or by any of the best PL trees).

Although both biogeographic methods suffer some pitfalls, the framework presented here is suitable for unravelling the biogeographic history of the Oreina AGS complex. Finally, to avoid inferring any misleading biogeographic relationships, only events shared between the two methods will be discussed.

\section{Dating analyses}

We applied the same strategy as in Bininda-Emonds et al. (2007) to estimate the divergence time between lineages in a maximum parsimony framework. First, maximum likelihood branch lengths of the best MP trees were estimated using PAUP* version 4.0b10 (Swofford 2002) based on the best-fit model. Second, these phylogenetic trees were dated using penalized likelihood (PL; Sanderson 2002) based on a secondary calibration point (i.e., the split between the Oreina AGS complex and its sister species) from previous analyses (M. Borer, unpublished data). Because of limitations related to the calibration point, only two outgroup species were kept $[O$. gloriosa and O. liturata (used as most external outgroup)] for the dating analysis. Relative branching times were first estimated on the majorityrule consensus using PL, as implemented in r8s v.1.71 (Sanderson 2004), and the Truncated Newton method algorithm. The smoothing value (100) was established using the cross-validation routines implemented in r8s. As required by r8s (see Sanderson 2004), the most external outgroup, O. liturata, was pruned for the estimation of the divergence time. To account for phylogenetic uncertainty in dating analysis, the PL method was applied to all best MP trees and subsequently summarized on the consensus tree following Buerki et al. (2011). The same smoothing value was used for all trees. TreeAnnotator (Drummond \& Rambaut 2007) was subsequently used to calculate mean values and $95 \%$ confidence intervals of age estimates from the sample of PL-dated trees for each node in the majority-rule consensus tree. The divergence time analysis was calibrated using a previous analysis (M. Borer, unpublished data) that estimated the split between $O$. gloriosa and the Oreina AGS complex at 2.12 million years ago (Mya) based on the average pairwise divergence substitution rates in insects for COI, COII and 16s rRNA (see Borer et al. 2010). This value was used as a fixed age in the PL analyses.

\section{Diversification analysis}

To provide an indication of diversification rates within the Oreina AGS complex, a semilogarithm lineagesthrough-time (LTT) plot was inferred using the R package LASER (Rabosky 2006). For each PL-dated tree, a LTT plot was generated, and subsequently, only the mean LTT plot was represented (following the same approach as in Couvreur et al. 2010). A procedure (scripted with the $R$ language; $\mathrm{R}$ Development Core Team 2009) was developed to detect putative increase in diversification based on LTT plots. This procedure aimed at recording inflexion points (as well as their ages) on LTT plots (scripts are available on request to SB). To retrieve a statistical framework, this procedure was performed over the set of PL-dated trees, and a 95\% interval of confidence was calculated (and subsequently represented on the mean LLT plot). Such an approach allowed to take into account phylogenetic and dating uncertainty on diversification analyses and also provided an interval of confidence for the shift in diversification rate. Results from the diversification analysis were investigated in the light of the biogeographic history and past climatic change, especially regarding the last glaciations that might have shaped the current diversity of the Oreina AGS complex. For the biogeography, MP-DIVA ancestral area reconstructions of nodes within the $95 \%$ of interval of confidence of diversification were extracted and vicariance and dispersal events taking place during this period recorded. For this part of the study, we have only considered results from the MP-DIVA analysis, because unlike the Mesquite approach, DIVA models speciation processes taking place at nodes (through the cladogenetic range evolution model) and is consequently more accurate.

\section{Tests of range expansion}

Signatures of demographic changes in each biogeographic region were examined by Tajima's D statistics (Tajima 1989) to investigate whether the Oreina AGS 
complex data departed from neutrality because of demographic factors such as population bottleneck or expansion. The examination of deviation from neutrality by the $\mathrm{D}$ index was computed using Arlequin 3.1 (Excoffier et al. 2005). The expectations of these statistics are approximately zero in a constant-size population. Significant negative values indicate a rapid expansion in population size, whereas significant positive values indicate processes such as a recent population subdivision or recent population bottlenecks.

\section{Results}

\section{Morphological determination}

Based on the shape of male genitalia, Kippenberg (1994, 2008) discriminates O. speciosa, O. ganglbaueri and five morphotypes within $O$. alpestris that correspond to at least eight previously reported subspecies (or forms). In our study, we could only distinguish four discrete genitalia types, represented in Fig. 1 together with their geographical distributions. The 'ganglbaueri' and 'speci$o s a^{\prime}$ genitalia types are easily diagnosable because of larger size (especially for 'ganglbaueri') and distinctive shapes at the distal end. The O. alpestris $\alpha$ and $\beta$ morphotypes that we defined here correspond to Kippenberg's morphotypes attributed to O. alpestris ssp. variabilis and $O$. alpestris ssp. alpestris, respectively. Interestingly, the type 'alpestris $\beta^{\prime}$ has an intermediate morphology between 'alpestris $\alpha$ ' and O. speciosa. Except in two populations, one in Abruzzi and one in the northern Carpathians, types 'alpestris $\alpha$ ' and 'alpestris $\beta$ ' were never found together. Moreover, type 'alpestris $\beta^{\prime}$ appears to be restricted to the edges of the distribution

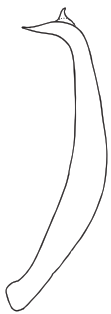

(a)
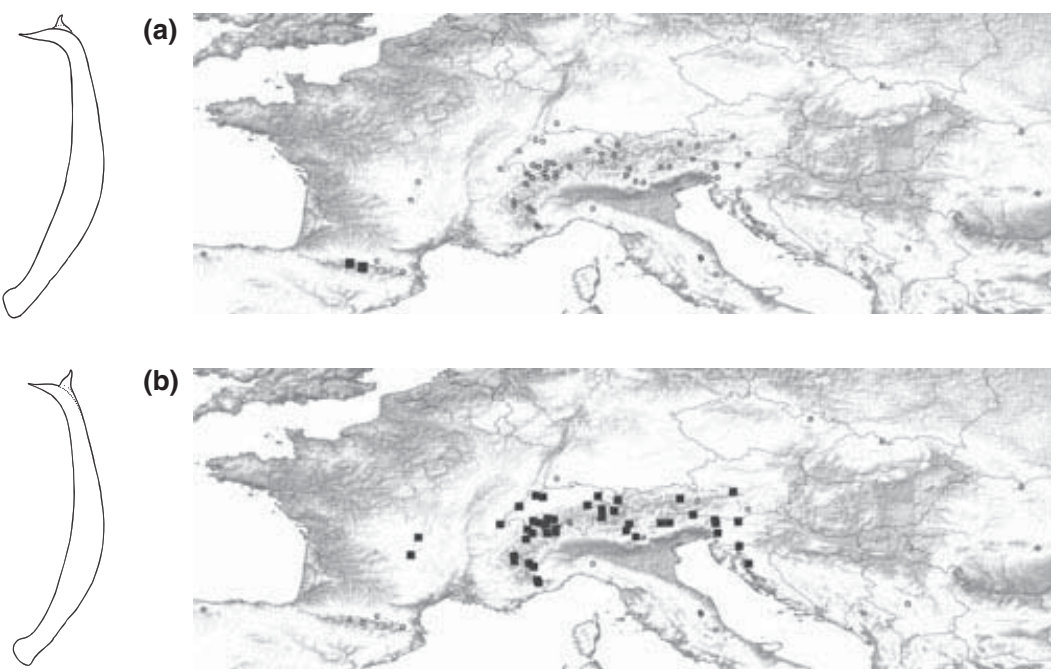

(b)

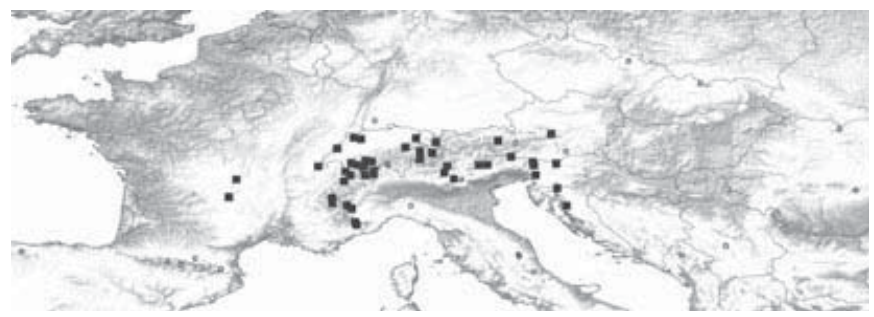

(c)
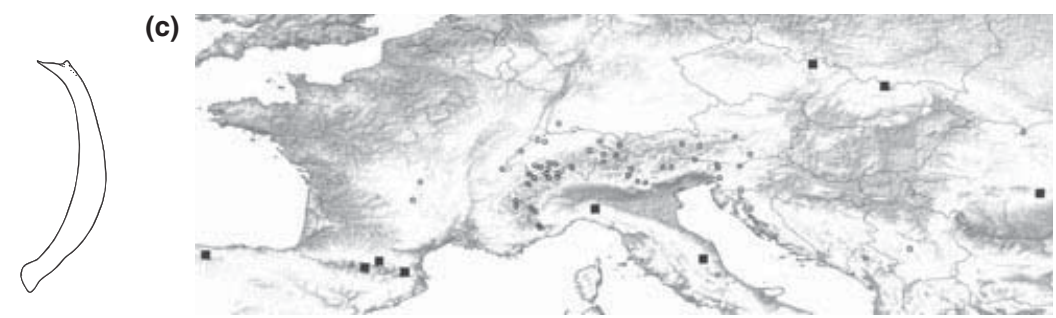

(d)

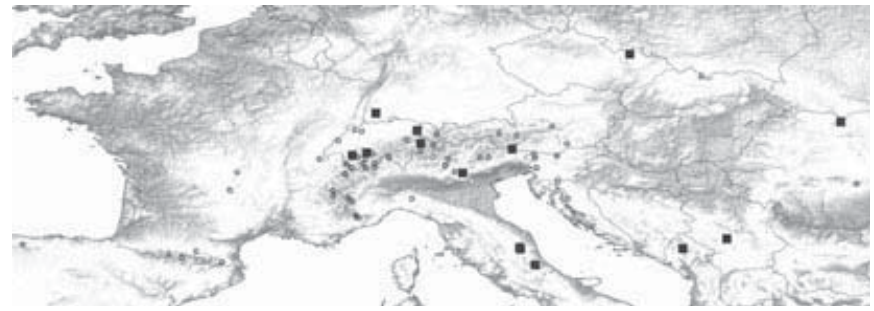

Fig. 1 Drawings of the four genitalia morphotypes examined in this study together with their distributions. (a) type ganglbaueri; (b) type speciosa; (c) type 'alpestris $\beta$ '; (d) type 'alpestris $\alpha$ '. The scale (shown at the bottom left) is identical for the four drawings. 
and was never found in the Alps. In contrast, all O. alpestris populations sympatric with $O$. speciosa (in other words, Alpine populations) always showed an 'alpestris $\alpha$ ' morphology. The 'alpestris $\alpha^{\prime} /$ 'alpestris $\beta^{\prime}$ genitalia classification only partially matches Kippenberg's O. alpestris subspecies: whereas the three subspecies alpestris, banatica and marsicana display both morphologies (sometimes even mixed within the same population), $O$. alpestris ssp. nigrina and O. alpestris ssp. variabilis strictly demonstrate 'alpestris $\alpha$ ' and 'alpestris $\beta^{\prime}$ genitalia types, respectively.

\section{Sequence polymorphism}

Amplification was successful at the mtDNA regions for 185 specimens and at ITS2 for 184 specimens (with 158 specimens amplified for both) (see Appendix S1 in Supporting information). The final alignment consisted of $1442 \mathrm{bp}$ for the three mtDNA regions: $513 \mathrm{bp}$ for $16 \mathrm{~s}$ rRNA [20 potentially parsimony informative (PPI) sites among 35 variable sites (VS) within the Oreina AGS complex], 345 bp for partial COI (54 PPI sites among 68 VS) and $584 \mathrm{bp}$ for partial COII (63 PPI sites among 85 VS). The total length of the nuclear ITS2 region was 611 bp (43 PPI sites among 73 VS). All sequences were deposited in GenBank (accession numbers GQ392138GQ392886). The best-fit substitution models for each of the four regions were as follows: Hasegawa-KishinoYano (HKY) model with a gamma parameter for ITS2 and 16s rRNA; General Time Reversible (GTR) model with a gamma parameter and a proportion of invariable sites for COI and COII.

\section{Genetic diversity}

Nucleotide diversities were computed in all populations where at least two individuals were collected (i.e., 60 of the 63 sampled populations). Values ranged between 0 and 0.048 , with most populations within the Alps showing high values. Diversities within each population are represented according to four classes in Fig. 2. The correlation between the number of analysed specimens per population and diversity values was low $\left(R^{2}=0.098\right)$.

\section{Barcoding analyses}

Based on the pairwise K2P distance matrix, two histograms were reconstructed to investigate the validity of the whole species complex as well as that of the single species within the complex (see Fig. 3 and Appendix S2 in Supporting information). For the latter, the outgroup species were not considered. Two major patterns can be seen in these histograms. First, the entire species complex formed a well-defined entity with respect to outgroups, with $\mathrm{K} 2 \mathrm{P}$ distances ranging from 0 to 0.08 (inter-taxa distances are generally higher than 0.08; Fig. 3a). Second, when the same approach was applied at the single-species level, the data showed that the boundaries between species were not clearly defined. The distances between members within each taxon were often greater than those among the three taxa (Fig. 3b). This result was even clearer when the species were considered separately. The pairwise K2P distance histograms for O. alpestris and O. speciosa covered the entire range of distances encountered within the species complex (see Appendix S2 in Supporting information). On the other hand, O. ganglbaueri exhibited a pattern coherent with species status, with K2P distances lower than 0.01 (see Appendix S2 in Supporting information). However, as it is nested in the Oreina AGS complex (see below), it might not deserve the status of species per se.

\section{MtDNA phylogenetic analyses}

The MP analysis yielded a well-resolved mtDNA majority-rule consensus tree, based on 125 equally parsimonious trees (650 steps; $\mathrm{CI}=0.55 ; \mathrm{RI}=0.89$ ). Monophyly of the Oreina AGS complex was confirmed with a Bremer value of two (Fig. 4). The MP phylogenetic hypothesis supported the monophyly of O. ganglbaueri (but nested within the other taxa), whereas $O$. alpestris and O. speciosa were shown to be paraphyletic. The Bayesian halfcompatible consensus tree confirmed the monophyly of the species complex and of O. ganglbaueri and the paraphyly of O. alpestris and O. speciosa (see Appendix S3 in Supporting information). However, basal lineages were slightly less resolved and supported in the Bayesian inference analysis (see Appendix S3 in Supporting information). Two topological differences were observed between the two methods: Oreina ganglbaueri diverged one step earlier in the MP analysis than in the Bayesian inference analysis, and a small group comprising five O. speciosa individuals from northern Italy (Dolomites and Piemonte regions; marked with a ' $\$$ ' on Fig. 4) fell in two different clades depending on the reconstruction method. As the two methods yielded highly similar results, only the MP topology will be discussed further because of its higher level of Bremer support in basal nodes. However, to define entities that were supported by both methods, we considered only main clades supported by Bremer indexes $\geq 1$ and BPP $\geq 0.8$, which diverged before the shift of diversification 0.36 Mya. By these criteria, the phylogenetic tree consists of seven major clades, referred to as M1-M7 (Fig. 4), each of them geographically structured (Fig. 5 and Appendix S4 in Supporting information) and suitable to perform MP-DIVA biogeographic analyses. 
(a)
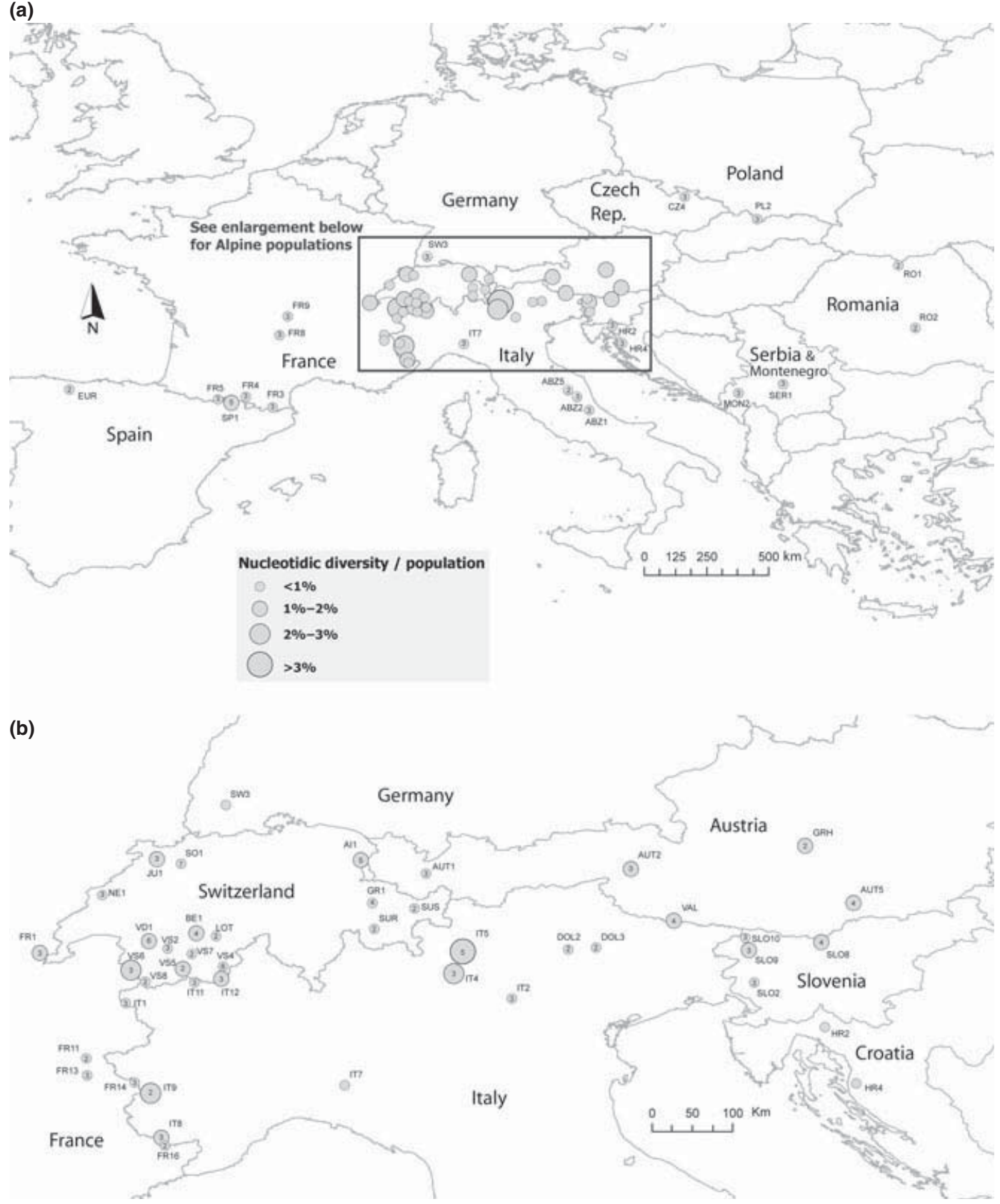

Fig. 2 Geographical representation of mtDNA nucleotide diversity values in each of the 60 populations of the Oreina AGS complex in which at least two specimens were sampled. (a) entire distribution; (b) enlargement for the Alpine area. The radius of each filled circle corresponds to one of the four classes of nucleotide diversity (see legend). Numbers in the circles give the number of specimens analysed in each population.

Finally, to investigate the phylogenetic species concept at the mtDNA clade level, pairwise K2P distance histograms were reconstructed for the seven mtDNA phylogenetic clades (Fig. 4). Three main patterns were recovered: (i) a unimodal distribution with K2P distances lower than 0.02 (clades M1, M2, M4); (ii) a unimodal distribution with $\mathrm{K} 2 \mathrm{P}$ distances lower than 0.04 (clade M6) and (iii) a bimodal distribution with the first group of distances ranging between 0 and 0.03 (clades M3, M5, M7). For the latter result, distances forming the second mode corresponded to specimens belonging to basal lineages within the three clades (Fig. 4). 
(a) Taxon level: Oreina AGS species complex

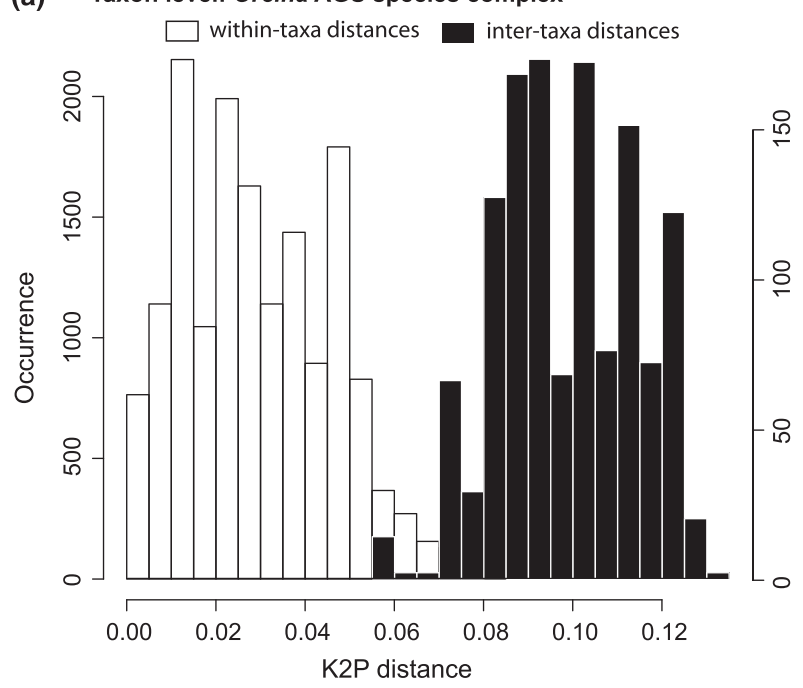

(b) Taxon level: single species within complex (O. alpestris, O. speciosa, O. ganglbaueri)

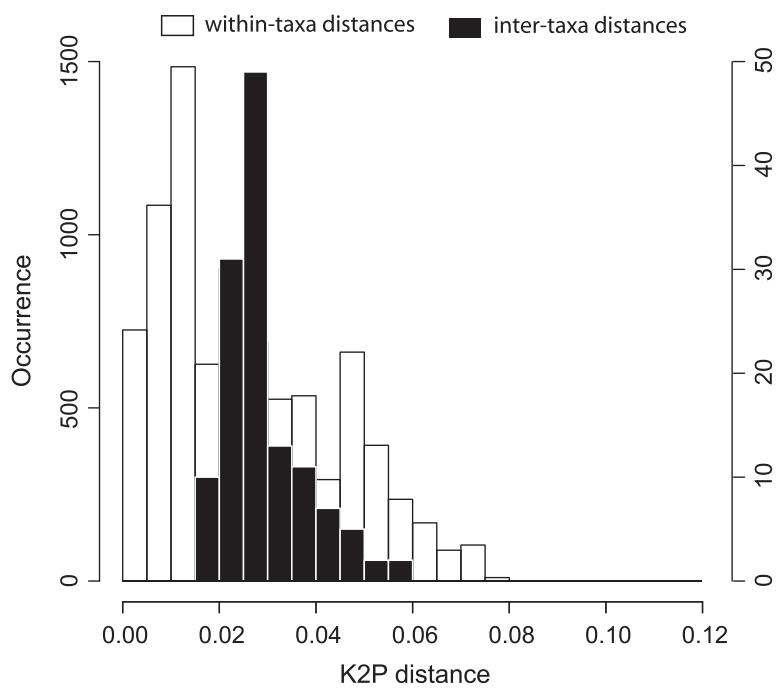

Fig. 3 Barcoding K2P distances histograms at the within- (in white) and among (in black)-taxa levels, considering both the Oreina AGS complex as a whole (a), and each single species within the complex separately (b).

\section{ITS2 phylogenetic analyses}

The MP analysis yielded an ITS2 majority-rule consensus tree based on 2009 equally parsimonious trees (78 steps; $\mathrm{CI}=0.85 ; \mathrm{RI}=0.93$ ). The resulting topology was, however, much less well resolved than the mtDNA topology for the ingroup taxa, and most samples were embedded in polytomies (Fig. 6). Bremer supports ranged from one to two for clades within the Oreina AGS complex, and O. speciosa, O. ganglbaueri and O. alpestris clustered together with a Bremer support of three. Again, only O. ganglbaueri was monophyletic (clade N1 in Fig. 6) among the three species, whereas O. alpestris and O. speciosa were mutually paraphyletic. This was also true in the half-compatible consensus tree obtained through the Bayesian inference analysis (data not shown). BPP and Bremer values were much lower than in the mtDNA analysis, but the monophyly of the ingroup was confirmed with high support $(\mathrm{BPP}=1.00$ and Bremer value $=3$ ), as was the monophyly of O. ganglbaueri $(\mathrm{BPP}=0.98$ and Bremer value $=2)$. Following the same approach as mentioned earlier, only clades supported by Bremer indices $\geq 2$ and BPP $\geq 0.95$ will be discussed in the light of the MP topology. The threshold levels were increased compared to the mtDNA analyses because we could not rely on a molecular-clock-based temporal framework that would have allowed inferring strong nuclear entities in our topology. Overall, only two clusters, referred to as N1 and $\mathrm{N} 2$, were well defined, both nested in a wide polytomy (referred to as N0; see Fig. 6). The Kishino-Hasegawa test strongly rejected congruence between the mtDNA and ITS data sets $(P$ value $<0.0001)$.

\section{Comparison between morphological and phylogenetic data}

To discuss the nature of inconsistencies among morphological, mtDNA and ITS2 data, we provide a contingency table (see Appendix S1 in Supporting information) containing information from unambigu-

Fig. 4 Majority-rule consensus tree of the MP analysis for the three mtDNA regions COI, COII and 16s rRNA in a total evidence approach. Label names comprise the biogeographic region (see map at the top left of the figure), the population code (see Table 1), the code of the individual specimen $(\mathrm{a}-\mathrm{g})$, followed by the genitalic morphology (ALP $\alpha$ for 'alpestris $\alpha$ ', ALP $\beta$, for 'alpestris $\beta$ ' GAN for 'ganglbaueri' and SPE for 'speciosa') for male specimens. In female specimens (marked with a '*'), the global body shape and morphology allowed us to distinguish the three species, coded by ALP, GAN and SPE (but with no way to separate ALP $\alpha$ and ALP $\beta$ ). Bremer support values are indicated on each node. Main clades are defined with codes from M1 to M7. The group illustrated with a ' $\$$ ' switched position between the MP and the Bayesian inference analyses (see Appendix S3 in Supporting information). On each node is represented a pie chart indicating the ancestral reconstruction of biogeographic areas following MP-DIVA (see text) with colours according to the legend. On the right, histograms inform on the K2P within-clade distance for M1 to M7. Additional modes '@', '\#' and ' $\$$ ' correspond to distances between basal clades or clans (sensu Wilkinson et al. 2007) with the rest of clades M3, M5 and M7, respectively. Nodes surrounded by a dashed circle correspond to the ten nodes that were found to fall within the $95 \%$ interval of confidence for the shift in diversification rate (see Fig. 8); roman letters associated with these nodes serve as a basis for Appendix S8 in Supporting information. 

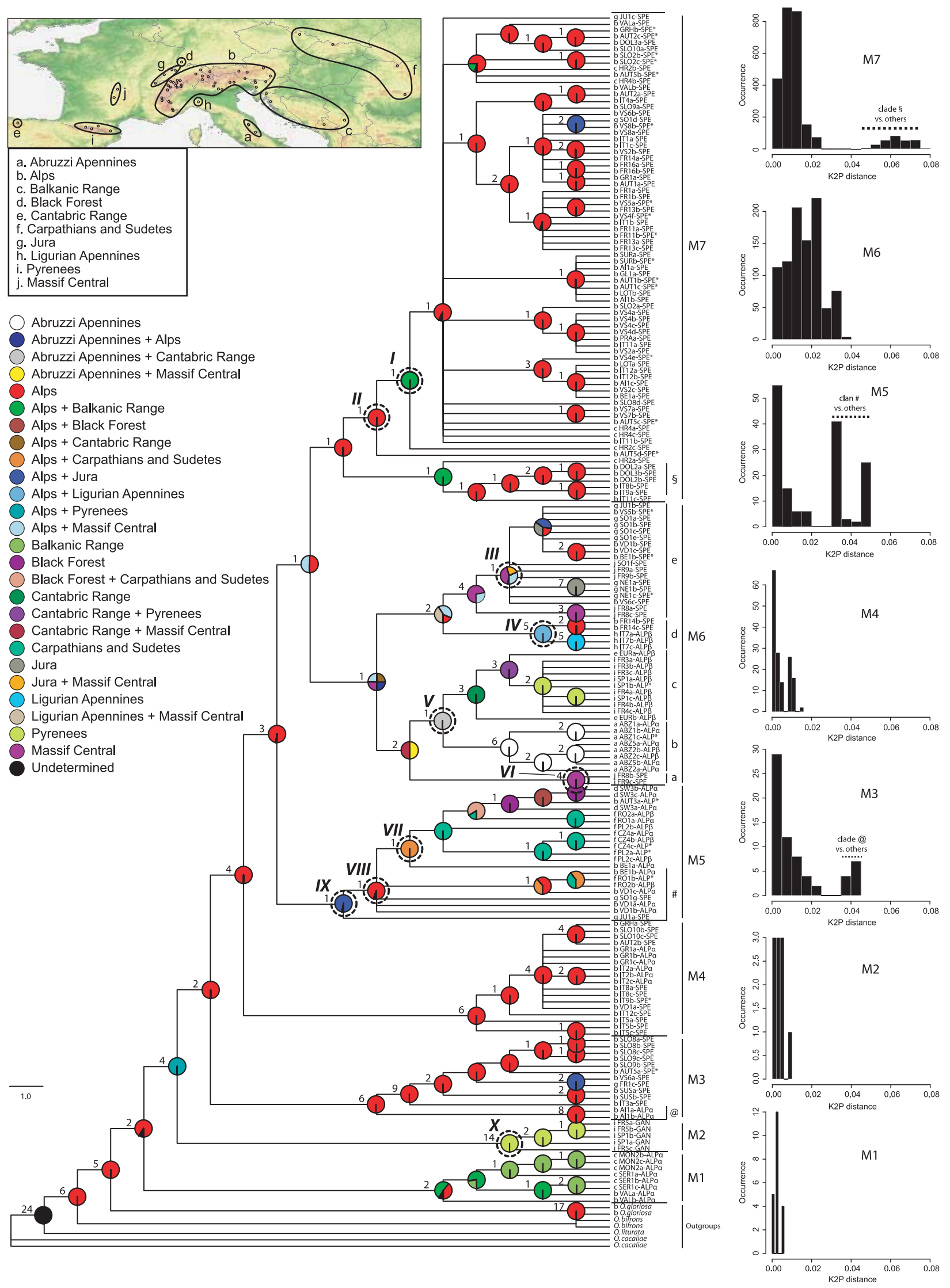

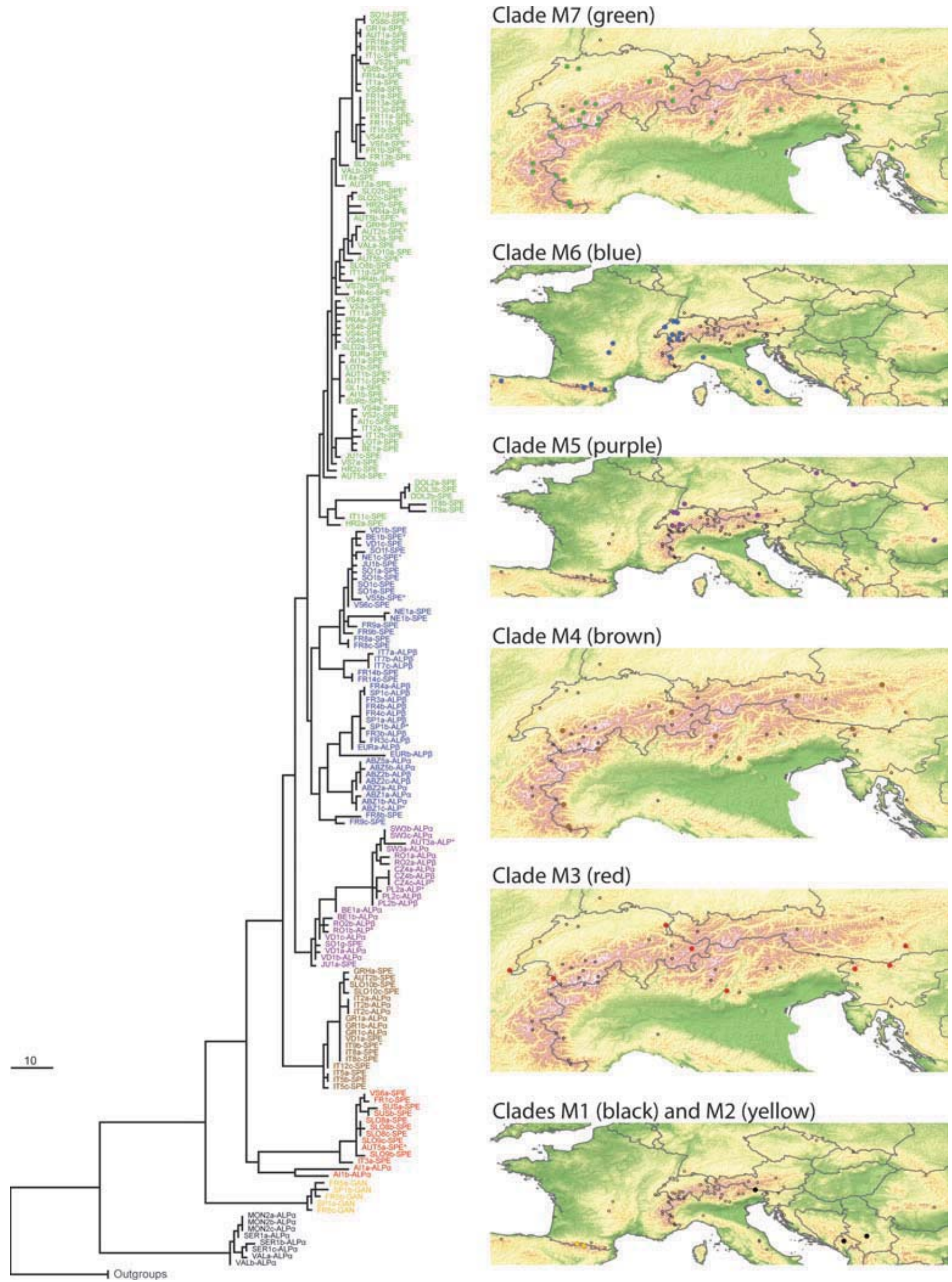

Fig. 5 One of the 125 equally parsimonious trees with main clades M1-M7 represented by different colours, together with their corresponding spatial distribution. 


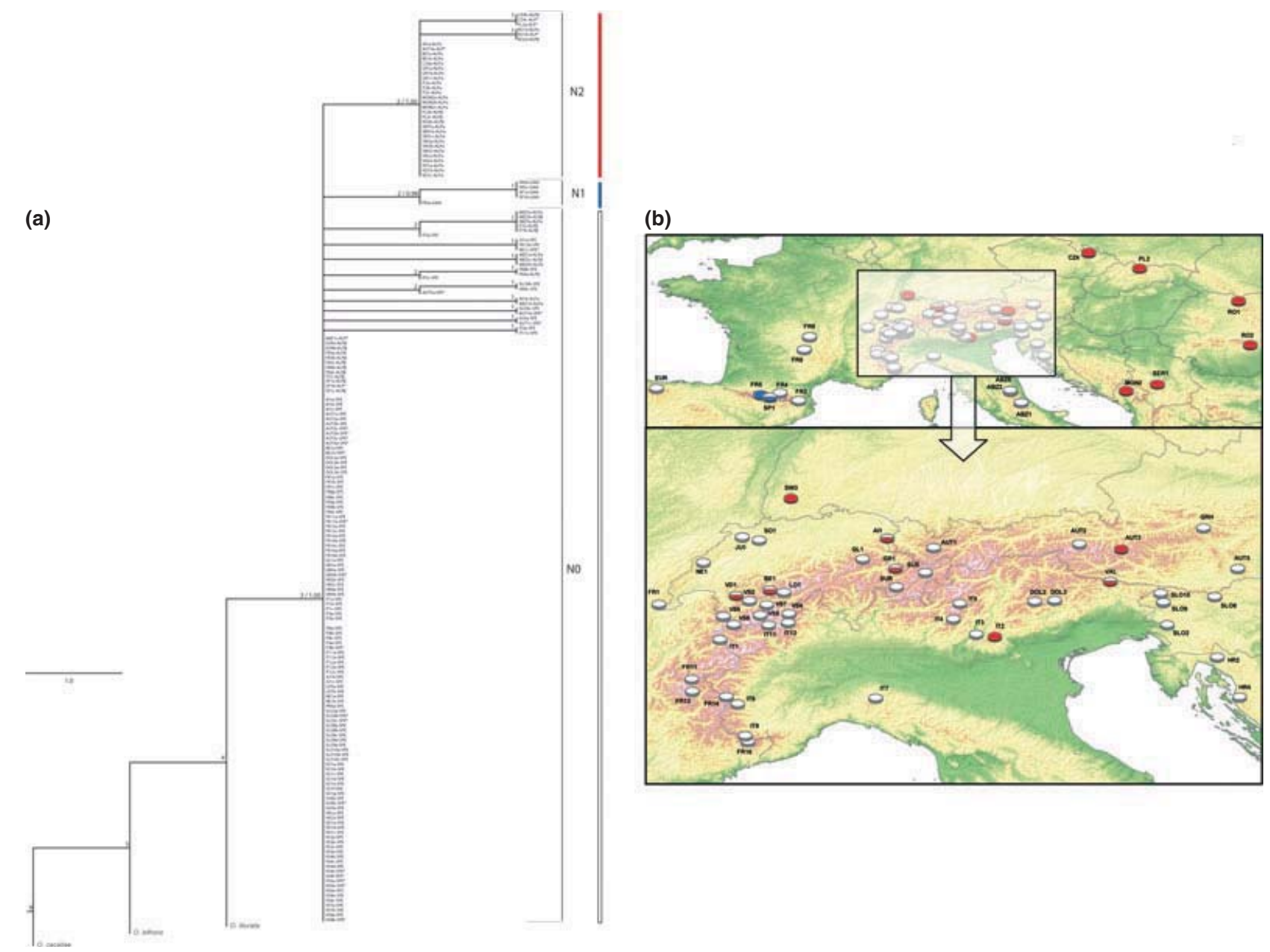

Fig. 6 Phylogeny and spatial distribution of major clades addressed with ITS2. (a) Majority-rule consensus tree (equal branch length cladogram) of the MP analysis for the nuclear region ITS2. Label names are identical to Fig. 4. Bremer support values and corresponding Bayesian Posterior Probabilities values are indicated on each node. The two main clades are defined with codes N1 and N2. Specimens that do not fall in a well-supported clade (N1 or N2) are considered as belonging to the wide polytomy N0. (b) Geographical distribution of each nuclear clade identified in the maximum parsimony analysis. Colours refer to N1 and N2 clades. Samples in white correspond to terminals falling in the NO polytomy.

ously determined specimens (excluding females and specimens with missing genetic information). Only the specimens of $O$. ganglbaueri are fully congruent between the morphology and each of the two genetic markers, with all individuals possessing the same genital morphology and falling into the same genetic clades (mtDNA clade M2 and ITS2 clade N1). The other clusters lack congruence across markers, for example ITS2 clade N2 includes two different genital types and four mtDNA clusters, the majority of which are also found in the ITS2 N0 polytomy. The same pattern is found with genital morphology types (other than 'O. ganglbaueri'), which include members of two to five mtDNA clades. Of these, few are specific to one single genital morphology (with the exceptions of M1 harbouring the 'alpestris $\alpha$ ' type and M7 having the 'speciosa' type), and some are found in three different genital types (M5 and M6).

\section{Biogeographic analysis}

The biogeographic scenario-ancestral range and main routes of dispersal-inferred from the MP-DIVA and Mesquite analyses is depicted in Figs 4 and 7 and Appendix S5 in Supporting information. As mentioned previously, to avoid overinterpretation of the results, only dispersal events shared between the two biogeographic methods will be presented here (see Appendix S6 in Supporting information and Fig. 7). With the only exception of clade M6-that has a high level of biogeo- 
graphic uncertainty-the two biogeographic scenarios provided highly congruent patterns. In the case of clade M6, it is interesting to notice that MP-DIVA suggested dispersals from the Alps (b) to the Apennines (a), the Massif Central (j) and the Cantabric range (e). These three events occurred during the main story (i.e., before the definition of main clades) in MP-DIVA (with some uncertainty; see Fig. 4) and took place in clade M6 in Mesquite (See Appendix S5 in Supporting information). In the case of MP-DIVA, the root node (including the Oreina AGS species complex and two outgroups) had a high level of uncertainty because of the wide distribution of the most external outgroup, O. cacaliae (which occurs in all ten areas; Fig. 4). The root node will therefore not be discussed further. A significant difference of dispersal events was observed between the two methods: 35 in Mesquite and 21 in MP-DIVA (see Appendix S6 in Supporting information). Such difference might be explained by the specificities of the biogeographic methods: DIVA assumes vicariance (and tends to postpone dispersal events to terminal branches), whereas Mesquite allows state changes (that can be considered as dispersals) across the whole phylogeny. Both methods had some uncertainty in the number and direction of dispersals within clade M6 caused by (i) its wide distribution and (ii) its higher phylogenetic uncertainty compared to the other clades. The methods concurred to infer the origin of the species complex to be in the Alps (b) with subsequent dispersals into the other mountain systems (Figs 4 and 7). Dispersal events were not equally distributed over the main lineages (see Fig. 7). For instance, clade M4 remained in the ancestral area (i.e., the Alps), whereas clades M5 and M6 colonized, respectively, the eastern and south-western mountain ranges (Fig. 7). Moreover, in several of the clades (M1, M2 and M3), only one dispersal event was recorded by the biogeographic analyses (Fig. 7). In addition to being the ancestral area, the Alps were shown to have acted as a meeting point for lineages after re-invasion-especially in clades M5 and M6 (Fig. 7)—suggesting that this region might be seen as a cross-roads. The Jura ( $\mathrm{g}$ ) seemed also to have been colonized several times during the Pleistocene history of the Oreina AGS complex (Fig. 7). Overall, no signature from recent demographic changes could be retrieved in contemporaneous popula- tions. Recent range expansion or retraction was rejected by Tajima's D test statistics in all biogeographic regions (see Appendix S7 in Supporting information).

\section{Dating analysis}

Once outgroup species were pruned (see above for more details), only 98 different best MP topologies were recognized instead of the previous 125 topologies. ML branch lengths were inferred for the best MP trees using a GTR model with an alpha parameter for the shape of the gamma distribution. Based on the secondary calibration point used in this study, the divergence time analysis estimated the origin of the Oreina AGS complex sometime during the Quaternary (more specifically during the Calabrian ca. $1.31 \mathrm{Mya}$ ) (Fig. 8). Although clade M1 is the sister lineage to the whole group, its most recent common ancestor (MRCA) diverged more recently (ca. 0.17 Mya) in the evolution of the Oreina AGS complex (Fig. 8). Such late divergence was also found for the MRCAs of clades M2-M4, which diverged during the Upper Pleistocene (Fig. 8). The last remaining clades (M5-M7) originated between 0.56 (clade M6) and 0.29 (clade M5) Mya (Fig. 8).

\section{Diversification analysis}

Based on the 98 LTT plots, a 95\% interval of confidence for the shift of diversification was inferred and represented on the mean LTT plot (Fig. 8). An increase in diversification was recognized between 0.36 and 0.18 Mya (Fig. 8). To investigate such a trend, the ancestral area reconstructions of the ten nodes (more specifically the branches including these nodes) within the interval of confidence were extracted and glacial and interglacial periods were considered (Fig. 8, Appendix S8 in Supporting information). To minimize any putative bias caused by biogeographic uncertainty on the understanding of the diversification of the Oreina AGS complex, only nodes (and consequently branches) that had ancestral area probabilities above 0.5 were considered. Nine nodes fulfilled this criterion, and once branches were extracted, the following biogeographic events were identified: six vicariance and four dispersal events (see Appendix S8 in Supporting information).

Fig. 7 Biogeographic scenario of the Oreina AGS complex inferred from MP-DIVA and Mesquite analyses. Only dispersals shared between the two methods are represented on the figure (see Appendix S6 in Supporting information). The biogeographic scenario is subdivided into two parts: (a) 'main story' from the root to the definition of the clades and (b) 'within-clade' summarizing events occurring in clades. In (a), squares represent clades whose most recent common ancestor (MRCA) dispersed (M1, M2) while circles indicate clades whose MRCA remained in the Alps. The dashed lines in clade M6 depict events that took place either at the main story level in MP-DIVA or at the within-clade level in Mesquite. The number of dispersals is represented on arrows as follows: MPDIVA/Mesquite. See Fig. 4 for area definitions. 
(a) Main biogeographic scenario (until definition of main clades)

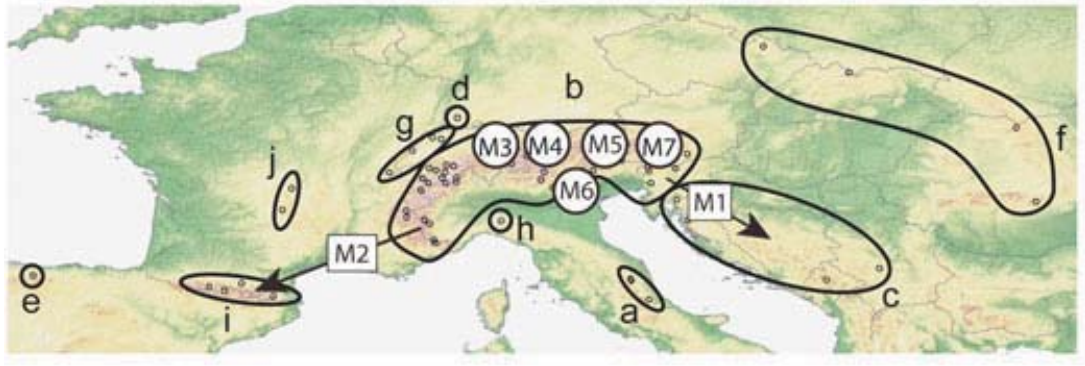

(b) Within-clades biogeographic scenarios

Clades M3
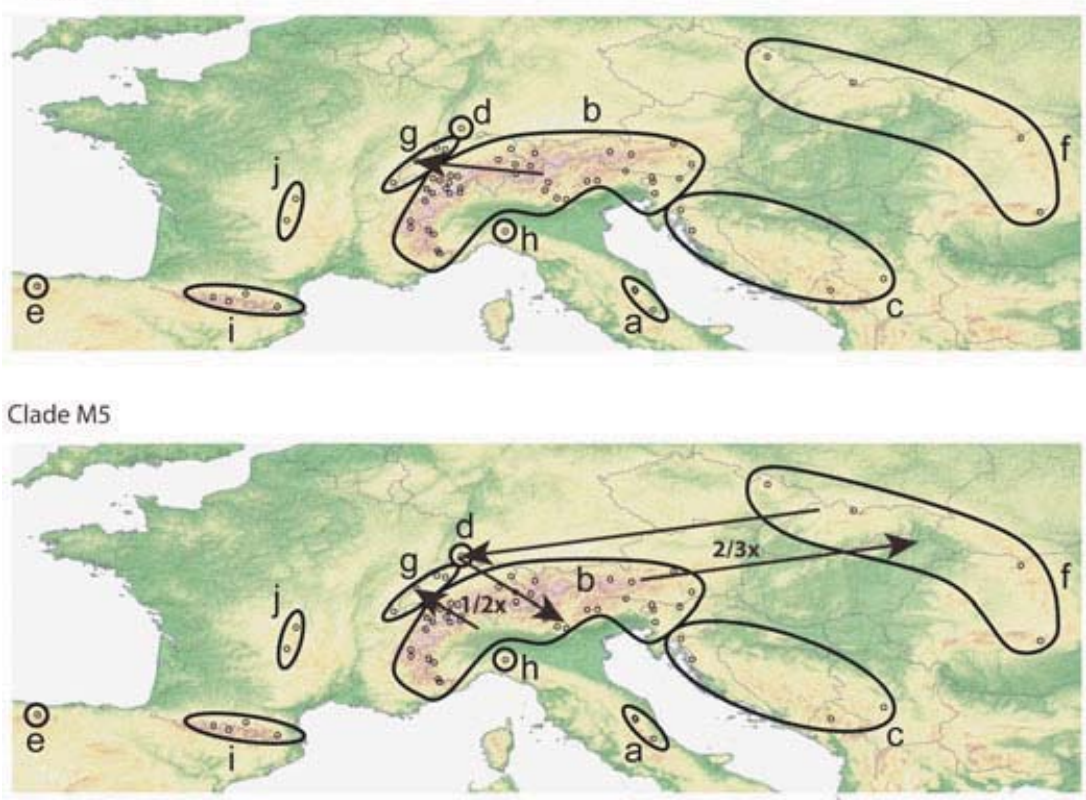

Clade M6

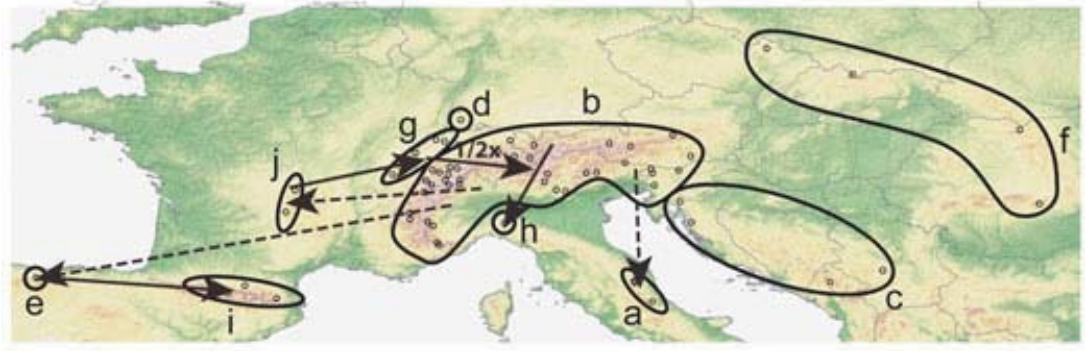

Clade M7

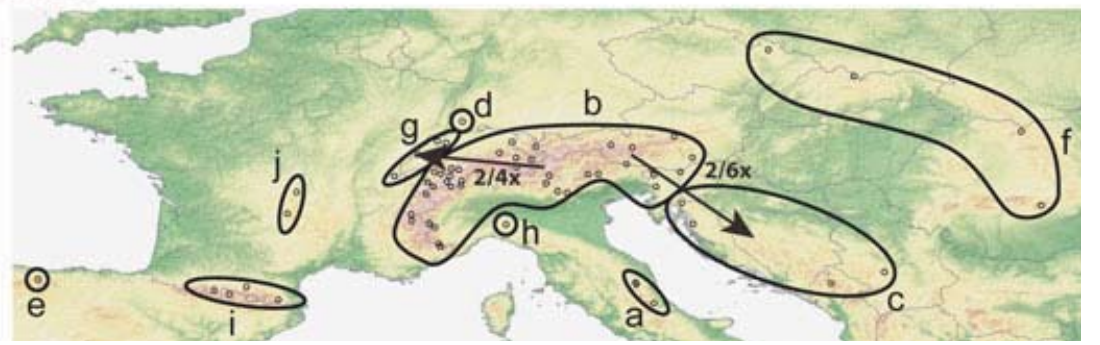




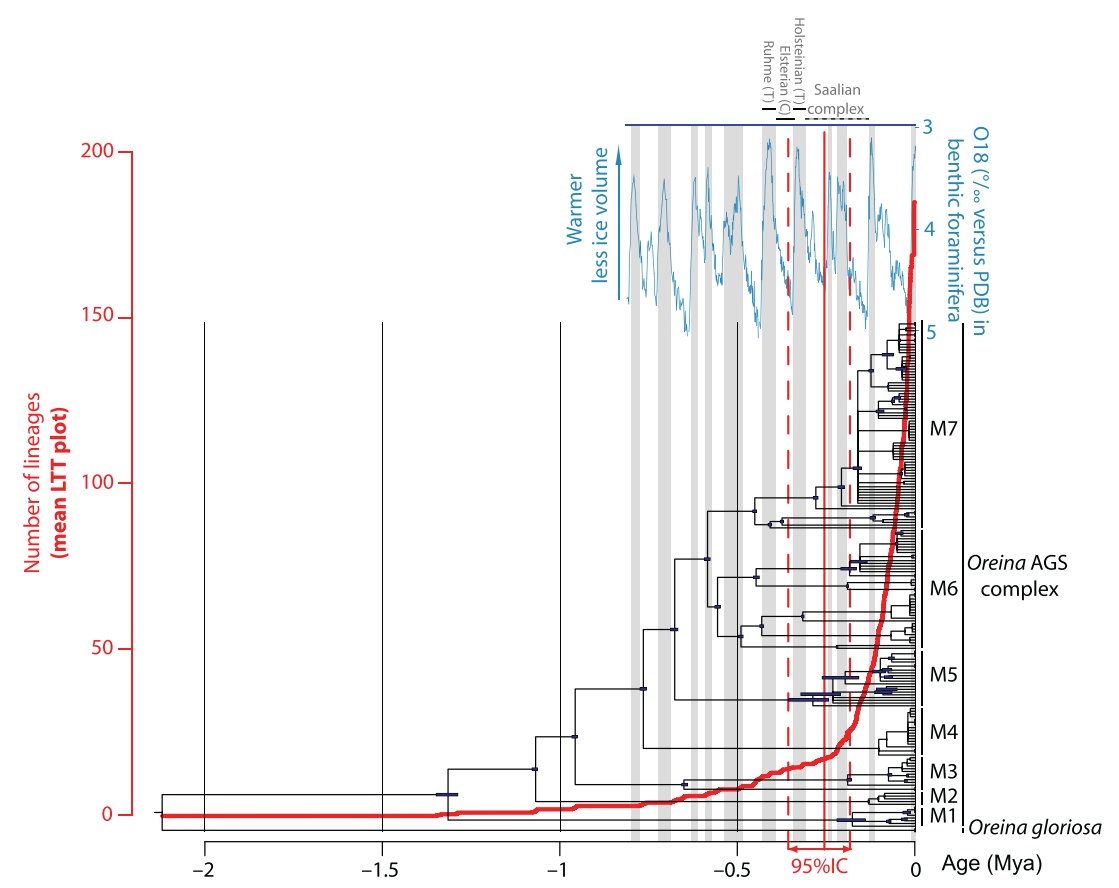

Fig. 8 Majority-rule consensus tree of the Oreina AGS complex (with its most closely related species, O. gloriosa), with median values and $95 \%$ confidence intervals for nodal ages as estimated by penalized likelihood over a sample of 98 best MP trees. The mean lineage through time (LTT) plot (in bold) is displayed on the phylogenetic tree together with the $95 \%$ interval of confidence (IC) for the shift in diversification rate. Finally, the changes in continental glaciation during the Quaternary (represented by the concentration of $0_{18}$ isotope in benthic foraminifera) are also presented (adapted from Sigman et al. 2010). Grey vertical bars reflect Temperate intervals (' $\mathrm{T}$ '), whereas white vertical bars indicate Cold intervals (' $\mathrm{C}$ '). The Saalian complex includes a succession of short cold and temperate periods and is considered either as a glacial or an interglacial period per se. More information on clade definitions is provided in Fig. 4. For additional details on the methodology applied here, please see the Material and methods section.

Five vicariance events involved the Alps (together with either the Balkanic range, the Carpathians and Sudetes, the Jura, the Ligurian Appenines or the Pyrenees), and all the dispersals were from the Alps to either the Jura (two times), the Carpathians and Sudetes or the Balkanic range (see Appendix S8 in Supporting information). These events mainly took place throughout clades M5M7. In the case of nine branches, no change of area was observed (see Appendix S8 in Supporting information).

Finally, when these results were investigated in the light of the past climate change, the diversification of the Oreina AGS complex was shown to occur over or just after a timeframe including two successive glacial and interglacial periods, from Ruhme to the beginning of the Saalian complex (Fig. 8).

\section{Discussion}

The species concept within the Oreina AGS complex: does taxonomy reflect biogeography?

Phylogenetic inferences support the monophyly of the Oreina AGS complex (Figs 4 and 6). Genetic distances consistent with the infra-specific level are confirmed by the barcoding approach (Fig. 3). In contrast, the monophyly of the species as currently defined is not supported (with the exception of O. ganglbaueri) and therefore should be revised (Figs 4 and 6). The most problematic species is $O$. speciosa, which has pairwise $\mathrm{K} 2 \mathrm{P}$ distances covering the entire range of distances encountered within the species complex and which is found in five of the seven mtDNA clades (usually together with specimens of $O$. alpestris, with the only exception of clade M7; Fig. 4). Although the taxonomic status of these two taxa seems problematic, the mtDNA clades exhibit strong identities based on barcoding evidence and might provide useful guidelines to define new taxon boundaries and find synapomorphies.

Although monophyletic and showing a strong genetic identity, specimens of O. ganglbaueri-mtDNA clade M2 and ITS2 clade N1-are nested within the two other species (Figs 4 and 6). This challenges the taxonomic identity of this species for the complex as currently described, but makes O. ganglbaueri an obvious candidate for species status if the complex were to be subdivided. From an evolutionary point of view, the taxon harbours a combination of unique features. First, 
O. ganglbaueri diverged very early in the evolution of the group (ca. 1.1 Mya), associated with dispersal from the Alps to the central valleys of the Pyrenees (Fig. 4 and 7). Second, perhaps as a result of this long-term isolation, the taxon has developed a unique type of male genitalia. When compared with the other species, $O$. ganglbaueri has by far the largest male genitalia (Fig. 1), a feature that could act as a physical pre-zygotic barrier. Finally, the strong morphological and genetic entity of $O$. ganglbaueri is attested by the apparent lack of introgression with specimens of $O$. alpestris (corresponding to the mtDNA clade M6), which is now sympatric after colonization of the Pyrenees from the Cantabric range (Figs 4, 5 and 7). The mtDNA phylogenetic framework reveals another example, clade M1, that is similar to the case of O. ganglbaueri. With the exception of one terminal tip (that occurs in the eastern Alps), this clade is restricted to the Balkans. As a whole, the long isolation of this clade (ca. 1.3 Mya, in an area that was only colonized twice during the history of the Oreina AGS complex; Fig. 7) together with a specific type of male genitalia ('alpestris $\alpha$ ') argues in favour of a very ancient history of this lineage that may have developed reproductive barriers despite its current sympatry with specimens of O. speciosa from clade M7.

The two well-circumscribed entities presented above contrast with the high level of morphological and molecular variation found in the rest of the species complex. This pattern is especially true in the Alps, which show the highest level of genetic diversity (Fig. 2). Such heterogeneity could be a product of the intricate history of dispersal and reinvasion in this region (Fig. 7). This dispersal would bring lineages into sympatry, opening the possibility of reinforcement and divergence of genitalic characters (Servedio \& Noor 2003), and also introgression. Our analyses clearly highlight that the taxa as currently circumscribed do not reflect the evolutionary history of the group, and therefore, we suggest considering the group as a species complex (as defined by Donoghue 1985; De Queiroz \& Donoghue 1988). Information from the phylogenetic tree and barcoding approach might provide useful guidelines to find morphological synapomorphies supporting these lineages (and consequently propose new species delimitations). Previous taxonomists working on Oreina have used the patterns of distribution to circumscribe subspecies (see Kippenberg 1994, 2008) and several of our clades match previous subspecies. For instance, the mtDNA clades M6b and M6c correspond to the microendemics $O$. alpestris ssp. marsicana from the Apennines and $O$. alpestris ssp. nigrina from the Pyrenees, respectively. This is also partly true for clade M1, which corresponds to O. alpestris ssp. balcanica (Wse.) described from Macedonia and Bulgaria (ranging from Serbia and Montenegro to southern Austria as shown here). Such correspondence is promising and suggests that further investigations will be able to provide a new taxonomic framework for the Oreina AGS complex.

The spatial history of the Oreina AGS complex: the Alps as a cross-roads triggering the radiation of the group across Europe

Our biogeographic results show that the success (or rate) of dispersal is lineage dependant. While some clades (M3, M4 and M7) were centrally located in the Alps and might thus have survived the last glaciations in this area, others demonstrated much greater dispersal abilities, such as clade M5 that moved mostly westwards, or clade M6 that moved eastwards (Figs 5 and 7). Mountain massifs other than the Alps could thus have provided appropriate climatic conditions for members of these two particular clades to survive severe climate shifts. According to the MP-DIVA analysis, the shift in the diversification of the Oreina AGS complex occurring during two successive glacial and interglacial periods seems to be correlated with an increase in vicariance events (Fig. 8). Such vicariance events should have occurred at the Ruhme or Holsteinian temperate interglacial events, following dispersal events associated with colder periods (e.g., Elsterian); alternate cold and temperate periods within the Saalian complex are also good candidates for successive dispersal and vicariance events that might have led to such lineage diversification. Even if congruent with the MP-DIVA inference in the overall biogeographic pattern, the Mesquite analysis does not allow confirmation or rejection of the hypothesis presented here (because Mesquite does not model cladogenetic range evolution on nodes). This hypothesis, although a promising line of research, remains to be formally tested in a full probabilistic framework. In view of our incompletely resolved phylogeny, a more sophisticated Lagrangebased cladogenetic range evolution model accounting for polytomies (that would not tend to overestimate vicariance over dispersal as in DIVA) still needs to be developed; such a feature will consequently require further work beyond the scope of this study.

The Alps were shown to be the most probable origin of the species complex (Fig. 4), especially when considering ancestral alpine lineages such as clades M3 and M4. Some distinct populations within these two clades, found for instance in western Dolomites (IT2, IT3), Adamello (IT5) and Swiss Inn valley (SUS), could indeed represent persistent refugia within the Alps, with further range expansion leaving just a few representatives at their eastern and western edges. Moreover, our 
results also strongly suggest that the Alps acted as an important cross-roads (Figs 4, 5 and 7). As shown by the MP-DIVA approach, several lineages reinvaded the region before dispersing onwards to other mountain chains during the shift in diversification rate that almost always involved the Alps and one neighbouring massif (see Appendix S8 in Supporting information). This radiation and reinvasion would explain the generally high genetic diversity in the Alps (Fig. 2), as would also its status of extensive refugial area (Pinceel et al. 2005; Pauls et al. 2006). As a consequence of its role as a cross-roads, the Alps show recurrent phylogeographic links with neighbouring massifs. As an illustration, clades M6d and M6e provide evidence of recent connection between the Alps and closely located Massif Central and Jura ranges. Clade M5 reveals biogeographic and genetic links between the Alps and Carpathians (such a link was also previously reviewed by Schmitt 2009). This particular connection might have been further facilitated by the presence of the Black Forest as an intermediately located massif, as clade M5 includes homogenous populations in the Carpathians and the Black Forest, both regions that may in addition represent cases of Northern refugia (Stewart \& Lister 2001; Pauls et al. 2009). The connection between the Black Forest and the Carpathians, however, represents a relatively unusual pattern (T. Schmitt pers. comm.). Finally, some patterns revealed here provide novel phylogeographic knowledge for the European mountain fauna. This is notably the case for the genetic connection between the Alps and Balkans (for which data were unavailable until now for insects according to Schmitt 2009): two mtDNA clades (M1 and M7) provide strong evidence for a relationship between (i) the eastern Alps and southern Balkans (Serbia and Montenegro) and (ii) the Alps (as a whole) and eastern Croatia. At least one of these two events occurred during the shift in diversification rate (see Appendix S8 in Supporting information).

Although less central to the biogeographic history of the Oreina AGS complex, it appears that the Jura might also have acted as a cross-roads by facilitating dispersal from south-western regions (from the Cantabric range and Massif Central) to the Alps (see clade M6; Fig. 7). This study also reveals the central Jura (clades M3, M5, M7) as a new area of importance in which similar processes of isolation followed by genetic divergence occurred during the late Pleistocene, thereby contributing to the intricacy of the biogeographic history of these alpine leaf beetles. This latter region actually shows, together with the Alps, the highest level of genetic diversity (Fig. 2).

The role of the Balkans and the Pyrenees is highlighted in the Oreina AGS biogeographic history through their roles in hosting the most ancestral refugial populations (represented by M1 and M2, respectively). As for other insect groups (Spooner \& Ritchie 2006; Varga \& Schmitt 2008; Rousselet et al. 2010), the importance of the Pyrenean range was in addition inferred for clade M6 (Figs 4, 5 and 7). The Pyrenees as well show recent connections with nearby massifs, such as the Cantabric range, Massif Central and Apennines (clades M6a,b,c). Similar to the Pyrenees, the importance of the Balkanic Peninsula as a main European refugial area (Previšić et al. 2009) is clearly attested in our results. Besides showing biogeographic links with the Alps, surprisingly, no such connection was shown between the Balkans and the Carpathians, despite relatively close proximity.

As a last note concerning the Carpathians (which were colonized twice, but by the same main lineage from clade M5; Fig. 7), we should note that no genetic differentiation could be detected (in mtDNA or nDNA) within the whole massif range, despite samples spanning the chain from north to south. This phylogenetic homogeneity in the Carpathians for the Oreina AGS complex contrasts with what has been found in Trichoptera (Pauls et al. 2006) as well as in angiosperms (e.g., Mraz et al. 2007; Ronikier et al. 2008), but also contrasts with the pattern found in most European mountain systems that were colonized several times by different clades.

In this study, the European high mountain Oreina AGS complex has been shown to be moulded by multiple evolutionary processes. Our dating analysis has placed the origin of this group at the mid-Pleistocene, with the shift in the diversification rate occurring between 0.18 and 0.36 Mya. Evaluating the respective importance of vicariance vs. dispersal in the diversification of the Oreina AGS complex still requires further investigations using cladogenetic range evolution models adapted to incompletely resolved phylogenies. Our biogeographic analysis reinforces the status of the Alps as a cross-roads for alpine insect species in Europe, as well as highlighting the important role of surrounding massifs such as the Jura, the Pyrenees and the western Balkans in their evolutionary history.

\section{Acknowledgements}

The authors thank three anonymous reviewers, Prof. Thomas Schmitt, as well as the associate editor Prof. Rosemary G. Gillespie, for useful comments on a previous version of this manuscript. This research was made possible thanks to the University of Neuchâtel and the National Centre of Competence in Research (NCCR 'Plant Survival'). NA was funded by the Swiss National Science Foundation (Ambizione fellowship PZ00P3_126624). The authors are very grateful to Y. Borcard for species determination and drawings of genitalia morphotypes and to N. Villard and F. Schüpfer for laboratory technical 
assistance. We also thank our precious field helpers: R. Arnoux, V. Baštić, A. Favre, A. Grill, N. Lamon and N. Margraf.

\section{References}

Akaike H (1974) New look at statistical-model identification. IEEE Transactions on Automatic Control, 19, 716-723.

Alvarez N, Thiel-Egenter C, Tribsch A et al. (2009) History or ecology? Substrate type as a major driver of spatial genetic structure in Alpine plants. Ecology Letters, 12, 632-640.

Bininda-Emonds ORP, Cardillo M, Jones KE et al. (2007) The delayed rise of present-day mammals. Nature, 446, 507-512.

Borer M, Alvarez N, Buerki S, Margraf N, Rahier M, Naisbit RE (2010) The phylogeography of an alpine leaf beetle: divergence within Oreina elongata spans several ice ages. Molecular Phylogenetics and Evolution, 57, 703-709.

Buerki S., Forest F, Alvarez N, Nylander JAA, Arrigo N, Sanmartín I. (2011) An evaluation of new parsimony-based versus parametric inference methods in biogeography: a case study using the globally distributed plant family Sapindaceae. Journal of Biogeography, 38, 531-550.

Coope GR (1994) The response of insect faunas to glacialinterglacial climatic fluctuations. Philosophical Transactions: Biological Sciences, 344, 19-26.

Couvreur TLP, Franzke A, Al-Shehbaz IA, Bakker FT, Koch MA, Mummenhoff K (2010) Molecular phylogenetics, temporal diversification, and principles of evolution in the mustard family (Brassicaceae). Molecular Biology and Evolution, 27, 55-71.

Dalén L, Nystrom V, Valdiosera C et al. (2007) Ancient DNA reveals lack of postglacial habitat tracking in the arctic fox. Proceedings of the national academy of sciences of the United States of America, 104, 6726-6729.

De Queiroz K, Donoghue MJ (1988) Phylogenetic systematics and the species problem. Cladistics, 4, 317-338.

Dobler S, Mardulyn P, Pasteels JM, Rowell-Rahier M (1996) Host-plant switches and the evolution of chemical defense and life history in the leaf beetle genus Oreina. Evolution, 50, 2373-2386.

Donoghue MJ (1985) A critique of the biological species concept and recommendations for a phylogenetic alternative. The Bryologist, 88, 172-181.

Drummond AJ, Rambaut A (2007) BEAST: Bayesian evolutionary analysis by sampling trees. BMC Evolutionary Biology, 7, 214.

Espíndola A, Buerki S, Bedalov M, Küpfer P, Alvarez N (2010) New insights into the phylogenetics and biogeography of Arum (Araceae): unravelling its evolutionary history. Botanical Journal of the Linnean Society, 163, 14-32.

Excoffier L, Laval G, Schneider S (2005) Arlequin (version 3.0): An integrated software package for population genetics data analysis. Evolutionary Bioinformatics Online, 1, 47-50.

Gelman A, Rubin DB (1992) Inference from iterative simulation using multiple sequences. Statistical Science, 7, 457-511.

Gomez-Zurita J, Vogler AP (2003) Incongruent nuclear and mitochondrial phylogeographic patterns in the Timarcha goettingensis species complex (Coleoptera, Chrysomelidae). Journal of Evolutionary Biology, 16, 833-843.

Habel JC, Meyer M, El Mousadik A, Schmitt T (2008) Africa goes Europe: the complete phylogeography of the marbled white butterfly species complex Melanargia galathea/M. lachesis (Lepidoptera: Satyridae). Organisms Diversity \& Evolution, 8, 121-129.

Hall TA (1999) Bioedit: a user-friendly biological sequence alignment editor and analysis program for Windows 95/98/NT. Nucleic Acids Symposium Series, 41, 95-98.

Haubrich K, Schmitt T (2007) Cryptic differentiation in alpineendemic, high-altitude butterflies reveals down-slope glacial refugia. Molecular Ecology, 16, 3643-3658.

Hebert PDN, Penton EH, Burns JM, Janzen DH, Hallwachs W (2004) Ten species in one: DNA barcoding reveals cryptic species in the neotropical skipper butterfly Astraptes fulgerator. Proceedings of the National Academy of Sciences of the USA, 101, 14812-14817.

Hewitt GM (2000) The genetic legacy of the Quaternary ice ages. Nature, 405, 907-913.

Hewitt GM (2001) Speciation, hybrid zones and phylogeography - or seeing genes in space and time. Molecular Ecology, 10, 537-549.

Hewitt GM (2004) Genetic consequences of climatic oscillations in the Quaternary. Philosophical Transactions of the Royal Society of London Series B-Biological Sciences, 359, 183-195.

Hsiao TH, Pasteels JM (1999) Evolution of host-plant affiliation and chemical defense in Chrysolina - Oreina leaf beetles as revealed by mtDNA phylogenies. In:Advances in Chrysomelidae Biology (ed. Cox ML), pp. 321-342. Backhuys, Leiden.

Huelsenbeck JP, Ronquist F (2001) MRBAYES: Bayesian inference of phylogenetic trees. Bioinformatics, 17, 754755.

Jolivet P, Petitpierre E, Daccordi M (1986) Les plantes-hôtes des Chrysomelidae. Quelques nouvelles précisions et additions (Coleoptera). Nouvelle Revue Entomologique, 3, 341-357.

Kalberer NM, Turlings TCJ, Rahier M (2005) An alternative hibernation strategy involving sun-exposed 'hotspots', dispersal by flight, and host plant finding by olfaction in an alpine leaf beetle. Entomologia Experimentalis et Applicata, 114, 189-196.

Kippenberg H (1994) Familie chrysomelidae. In: Die Käfer Mitteleuropas, 3. Supplementband (ed. Lohse GA, Lucht WH), pp. 65-83. Krefeld, Germany.

Kippenberg H (2008) Revision der untergattung Protorina WEISE der gattung Oreina CHEVROLAT (Coleoptera: Chrysomelidae: Chrysomelinae). Koleopterologische Rundschau, 78, 367-418.

Knoll S, Rowell-Rahier M (1998) Distribution of genetic variance and isolation by distance in two leaf beetle species: Oreina cacaliae and Oreina speciosissima. Heredity, 81, 412-421.

Maddison WP, Maddison DR (2010) Mesquite: a modular system for evolutionary analysis. Version 2.73. Available at http:/ /mesquiteproject.org. Accessed on 7 March 2011.

Mardulyn P, Milinkovitch MC, Pasteels JM (1997) Phylogenetic analyses of DNA and allozyme data suggest that Gonioctena leaf beetles (Coleoptera; Chrysomelidae) experienced convergent evolution in their history of host-plant family shifts. Systematic Biology, 46, 722-747.

Margraf N, Verdon A, Rahier M, Naisbit RE (2007) Glacial survival and local adaptation in an alpine leaf beetle. Molecular Ecology, 16, 2333-2343.

Mraz P, Gaudeul M, Rioux D et al. (2007) Genetic structure of Hypochaeris uniflora (Asteraceae) suggests vicariance in the 
Carpathians and rapid post-glacial colonization of the Alps from an eastern Alpine refugium. Journal of Biogeography, 34, 2100-2114.

Nei M (1987) Molecular Evolutionary Genetics. Columbia University Press, New York.

Nixon KC (1999) The Parsimony Ratchet, a new method for rapid parsimony analysis. Cladistics-the International Journal of the Willi Hennig Society, 15, 407-414.

Nylander JAA (2004) MrAIC.pl (v1.4.4). Program Distributed by the Author. Evolutionary Biology Centre, Uppsala University, Uppsala, Sweden.

Nylander JAA, Ronquist F, Huelsenbeck JP, Nieves-Aldrey JL (2004) Bayesian phylogenetic analysis of combined data. Systematic Biology, 53, 47-67.

Nylander JAA, Olsson U, Alström P, Sanmartín I (2008) Accounting for phylogenetic uncertainty in biogeography: a Bayesian approach to dispersal-vicariance analysis of the thrushes (Aves: Turdus). Systematic Biology, 57, 257-268.

Paradis E (2010) pegas: an R package for population genetics with an integrated-modular approach. Bioinformatics, 26, 419-420.

Paradis E, Claude J, Strimmer K (2004) APE: analyses of phylogenetics and evolution in R language. Bioinformatics, 20, 289-290.

Pauls SU, Lumbsch HT, Haase P (2006) Phylogeography of the montane caddisfly Drusus discolor: evidence for multiple refugia and periglacial survival. Molecular Ecology, 15, 21532169.

Pauls SU, Theissinger $\mathrm{K}$, Ujvarosi L, Balint $\mathrm{M}$, Haase $\mathrm{P}$ (2009) Patterns of population structure in two closely related, partially sympatric caddisflies in Eastern Europe: historic introgression, limited dispersal, and cryptic diversity. Journal of the National American Benthological Society, 28, 517-536.

Pinceel J, Jordaens K, Pfenninger M, Backeljau T (2005) Rangewide phylogeography of a terrestrial slug in Europe: evidence for Alpine refugia and rapid colonization after the Pleistocene glaciations. Molecular Ecology, 14, 1133-1150.

Planet PJ, Sarkar IN (2005) mILD: a tool for constructing and analyzing matrices of pairwise phylogenetic character incongruence tests. Bioinformatics, 21, 4423-4424.

Previšić A, Walton C, Kučinić M, Mitrikeski PT, Kerovec M (2009) Pleistocene divergence of Dinaric Drusus endemics (Trichoptera, Limnephilidae) in multiple microrefugia within the Balkan Peninsula. Molecular Ecology, 18, 634-647.

$\mathrm{R}$ Development Core Team (2009) A language and environment for statistical computing. Available at http:// www.R-project.org. Accessed on 7 March 2011.

Rabosky DL (2006) LASER: a maximum likelihood toolkit for detecting temporal shits in diversification rates from molecular phylogenies. Evolutionary Bioinformatics Online, 2, 257-260.

Rambaut A, Drummond AJ (2008) Tracer v1.4.1. Distributed by the Authors. Institute of Evolutionary Biology, University of Edinburgh, Edinburgh, UK. Available at http:// tree.bio.ed.ac.uk/software/tracer. Accessed on 7 March 2011.

Ree RH, Smith SA (2008) Maximum likelihood inference of geographic range evolution by dispersal, local extinction, and cladogenesis. Systematic Biology, 57, 4-14.

Ronikier M, Cieslak E, Korbecka G (2008) High genetic differentiation in the alpine plant Campanula alpina Jacq.
(Campanulaceae): evidence for glacial survival in several Carpathian regions and long-term isolation between the Carpathians and the Alps. Molecular Ecology, 17, 17631775.

Ronquist F (1996) DIVA 1.2. Computer programme distributed by the author. Available at http:// ceb.csit.fsu.edu/ronquistlab/downloads.php. Accessed on 7 March 2011.

Ronquist F (1997) Dispersal-vicariance analysis: a new approach to the quantification of historical biogeography. Systematic Biology, 46, 195-203.

Rousselet J, Zhao RX, Argal D et al. (2010) The role of topography in structuring the demographic history of the pine processionary moth, Thaumetopoea pityocampa (Lepidoptera: Notodontidae). Journal of Biogeography, 37, 1478-1490.

Sanderson M.J. (2002) Estimating absolute rates of molecular evolution and divergence times: a penalized likelihood approach. Molecular Biology and Evolution, 19, 101-109.

Sanderson M.J. (2004) r8S, program and documentation. Available at http://loco.biosci.arizona.edu/r8s/. Accessed on 7 March 2011.

Schmitt T (2007) Molecular biogeography of Europe: Pleistocene cycles and postglacial trends. Frontiers in Zoology, 4, 13.

Schmitt T (2009) Biogeographical and evolutionary importance of the European high mountain systems. Frontiers in Zoology, 6, 9 .

Schmitt T, Rober S, Seitz A (2005) Is the last glaciation the only relevant event for the present genetic population structure of the meadow brown butterfly Maniola jurtina (Lepidoptera : Nymphalidae)? Biological Journal of the Linnean Society, 85, 419-431.

Schmitt T, Hewitt GM, Muller P (2006) Disjunct distributions during glacial and interglacial periods in mountain butterflies: Erebia epiphron as an example. Journal of Evolutionary Biology, 19, 108-113.

Servedio MR, Noor MAF (2003) The role of reinforcement in speciation: theory and data meet. Annual Review of Ecology and Systematics, 34, 339-364.

Shapiro B, Drummond AJ, Rambaut A et al. (2004) Rise and fall of the Beringian steppe bison. Science, 306, 1561-1565.

Sigman DM, Hain MP, Haug GH (2010) The polar ocean and glacial cycles in atmospheric $\mathrm{CO} 2$ concentration. Nature, 466, 47-55.

Sikes DS, Lewis PO (2001) Software Manual for PAUPRat: A Tool to Implement Parsimony Ratchet Searches using PAUP*. University of Connecticut, Storrs, CT.

Simon C, Frati F, Beckenbach A et al. (1994) Evolution, weighting, and phylogenetic utility of mitochondrial genesequences and a compilation of conserved polymerase chainreaction primers. Annals of the Entomological Society of America, 87, 651-701.

Sorenson MD, Franzosa EA (2007) TreeRot, Version 3. Boston University, Boston, MA.

Spooner LJ, Ritchie MG (2006) An unusual phylogeography in the bushcricket Ephippiger ephippiger from Southern France. Heredity, 97, 398-408.

Stewart JR, Lister AM (2001) Cryptic northern refugia and the origins of the modern biota. Trends in Ecology \& Evolution, 16, 608-613. 
Stewart JR, Lister AM, Barnes I et al. (2010) Refugia revisited: individualistic responses of species in space and time. Proceedings of the Royal Society B-Biological Sciences, 277, 661671.

Swofford DL (2002) PAUP*. Phylogenetic Analysis Using Parsimony ("and other Methods), Version 4.0b10. Sinauer Associates, Sunderland, MA.

Tajima F (1989) Statistical method for testing the neutral mutation hypothesis by DNA polymorphism. Genetics, 123, 585-595.

Thompson JD, Gibson TJ, Plewniak F, Jeanmougin F, Higgins DG (1997) The clustalX windows interface: flexible strategies for multiple sequence alignment aided by quality analysis tools. Nucleic Acids Research, 24, 4876-4882.

Triponez Y, Naisbit RE, Jean-Denis JB, Rahier M, Alvarez N (2007) Genetic and environmental sources of variation in the autogenous chemical defense of a leaf beetle. Journal of Chemical Ecology, 33, 2011-2027.

Varga ZS, Schmitt T (2008) Types of oreal and oreotundral disjunctions in the western Palearctic. Biological Journal of the Linnean Society, 93, 415-430.

Wiemers M, Fiedler K (2007) Does the DNA barcoding gap exist? - a case study in blue butterflies (Lepidoptera: Lycaenidae). Frontiers in Zoology, 4, 8.

Wilkinson M, McInerney JO, Hirt RP, Foster PG, Embley TM (2007) Of clades and clans: terms for phylogenetic relationships in unrooted trees. Trends in Ecology \& Evolution, 22, 114-115.

Willis KJ, van Andel TH (2004) Trees or no trees? The environments of central and eastern Europe during the Last Glaciation. Quaternary Science Reviews, 23, 2369-2387.

Yang ZH (1994) Maximum-Likelihood phylogenetic estimation from DNA-sequences with variable rates over sitesapproximate methods. Journal of Molecular Evolution, 39, 306314.

Y.T. completed his PhD at the University of Neuchâtel (Switzerland) in the field of phylogeography and ecology of specific plant-insect interactions. S.B. is a post-doctoral fellow at the Kew Royal Botanic Gardens (UK), funded by a Marie-Curie Fellowship. His research is focused on understanding the spatio-temporal evolution of various plant and insect groups. $\mathrm{He}$ is also interested in the development of new methods in the field of biogeography. M.B. is an entomology curator at the Natural History Museum of Neuchatel (Switzerland), interested in the phylogeny and phylogeography of leaf beetles.
R.N. works on the ecology and evolution of Oreina leaf beetles, on community ecology in wildflower strips, and on metaanalyses of food webs. M.R. is a Professor in entomology at the University of Neuchãtel. N.A. is a research associate at the University of Lausanne (Switzerland), interested in the evolution of plant-insect interactions at different scales of time and space.

\section{Supporting information}

Additional supporting information may be found in the online version of this article.

Appendix S1 Contingency table showing the number of individuals crossclassified by morphological categories, mtDNA and nuclear phylogenetic clades.

Appendix S2 Detailed K2P barcoding distances within each species (O. alpestris, $O$. speciosa, $O$. ganglbaueri).

Appendix S3 Half-compatible topology of the MrBayes analysis, with the corresponding BPP and Bremer support values on each node.

Appendix S4 All-in-one geographical distribution of each mtDNA clade identified in the MP analysis (see Fig. 4).

Appendix S5 Biogeographic history of the Oreina AGS complex inferred from the likelihood method implemented in Mesquite and represented on the PL dated Majority-rule consensus tree.

Appendix S6 Summary of the biogeographic scenarios of the Oreina AGS complex inferred from the MP-DIVA and Mesquite ancestral area reconstructions (see text for more details on the protocol to extract biogeographic events from the reconstructions).

Appendix S7 Tajima's D test parameters for each biogeographic region.

Appendix S8 Geographic events for each of the ten nodes included in the $95 \%$ inflexion-point interval of the diversification rate (see Fig. 8), as highlighted in Fig. 4. 